\title{
Model selection in statistical historical biogeography of Neotropical insects-the Exophthalmus genus complex (Curculionidae: Entiminae)
}

Guanyang Zhang ${ }^{\mathrm{a}^{*}}$

${ }^{a}$ School of Life Sciences, Arizona State University, Tempe, Arizona 85287, USA

* Corresponding author

Usmaan Basharat ${ }^{\mathrm{a}, \mathrm{b}, 1}$ guanyang.zhang@asu.edu

${ }^{a}$ School of Life Sciences, Arizona State University, Tempe, Arizona 85287, USA

${ }^{\mathrm{b}}$ Undergraduate Research Program (SOLUR), School of Life Sciences, Arizona State University, Tempe, Arizona 85287, USA basharat.usmaan@gmail.com

Nicholas Matzke ${ }^{\mathrm{c}, 2}$

${ }^{c}$ National Institute for Mathematical and Biological Synthesis, 1122 Volunteer Boulevard, Suite 106. University of Tennessee, Knoxville, Tennessee 37996, USA nickmatzke.ncse@gmail.com

\section{Nico M. Franz ${ }^{\mathrm{a}}$}

${ }^{a}$ School of Life Sciences, Arizona State University, Tempe, Arizona 85287, USA nico.franz@asu.edu

Keywords: Caribbean biogeography, dispersal, molecular dating, statistical biogeography, West Indies

\section{Abbreviations ${ }^{3}$}

${ }^{1}$ Current address: The University of Arizona College of Medicine - Phoenix, Phoenix, Arizona 85004, USA.

${ }^{2}$ Current address: The Australian National University, Canberra, Australian Capital Territory 2601, Australia.

${ }^{3}$ EGC, Exophthalmus genus complex; FEJD, founder event jump dispersal; Ma, million-years ago; Myr, million years 


\section{ABSTRACT}

Statistical historical biogeographic methods rely on models that represent various biogeographic processes. Until recently model selection in this domain was not widely used, and the impact of differential model selection on inferring biogeographic scenarios was not well understood. Focusing on Neotropical weevils in the Exophthalmus genus complex (EGC) (Insecta: Curculionidae: Entiminae), we compare three commonly used biogeographic models - DIVA (Dispersal-Vicariance Analysis), DEC (Dispersal-Extinction-Cladogenesis) and BayArea (Bayesian Analysis of Biogeography), and examine the impact of modeling founder-event jump dispersal on historical biogeographic reconstructions. We also investigate the biogeographic events that have shaped patterns of distribution, diversification, and endemism in this weevil lineage. We sample representatives of 65 species of the EGC and 26 outgroup terminals from the Neotropics, including Caribbean islands and the mainland. We reconstruct a molecular phylogeny based on six genes and apply molecular dating using a relaxed clock with three fossil calibration points. Historical biogeographic estimations and compare alternative biogeographic models are computed with the R package BioGeoBEARS. Model selection strongly favors biogeographic models that include founder-event jump dispersal. Without modeling jump dispersal, estimations based on the three biogeographic models are dramatically different, especially for early-diverging nodes. When jump dispersal is included, the three biogeographic models perform similarly. Accordingly, we show that the Neotropical mainland was colonized by Caribbean species in the early Miocene, and that in situ diversification accounts for a majority $(\sim 75 \%)$ of the biogeographic events in the EGC. Our study highlights the need to assess wide-ranging historical biogeographic processes including founder-event jump dispersal - for best-fitting statistical Caribbean biogeography reconstructions. Moreover, colonization of the Neotropical mainland from the Caribbean islands reinforces the notion that islands can be an important source of continental diversity.

\section{INTRODUCTION}

Methods in parametric historical biogeography are founded upon models of geographic range evolution, and therefore entail specific assumptions about biogeographic processes or range inheritance scenarios (Matzke, 2013a; Ree et al., 2005). These processes can be anagenetic or cladogenetic, including different range-evolution scenarios such as dispersal (range expansion), extinction (range contraction), sympatry, vicariance, and FEJD (founder-event jump dispersal; Matzke, 2013a; Ree \& Smith, 2008). Three widely used biogeographic models - DEC (Dispersal-Extinction-Cladogenesis; Ree \& Smith, 2008; Ree et al., 2005), DIVA (Dispersal- Vicariance Analysis; Nylander et al., 2008; Ronquist, 1997; Yu et al., 2010) and BayArea (Bayesian Analysis of Biogeography; Landis et al., 2013) each stipulate different sets of biogeographic processes (see Matzke, 2013a). Until recently, model-based historical biogeographic studies did not explicitly focus on model selection. Statistical testing of the fit of alternative biogeographic models to phylogenetic and distributional data remains at an early-stage development level for this domain, in contrast to strictly phylogenetic inferences where model selection is well established and diversified (Goldman, 1993; Hansen, 1997; O’Meara, 2012; Posada \& Crandall, 1998). Accordingly, the specific contingencies of model choice on particular biogeographic inferences, and rationales for model selection, are also still poorly understood.

Here we focus on a large insect radiation, the Exophthalmus genus complex (henceforth EGC) (Insecta: Curculionidae: Entiminae), distributed throughout the Caribbean archipelago and Neotropical mainland, and thoroughly explore the effects of model selection on historical biogeographic inferences. Using the R package BioGeoBEARS (Matzke, 2013b, 2014), we test the parametric fit of three models - DEC, DIVA and BayArea - in relation to a 
new phylogeny and documented distributional patterns of EGC members (note: DIVALIKE and BAYAREALIKE are likelihood implementations of the original models). We focus in particular on the significance of adding founder-event jump dispersal (FEJD) into these models, given that this process is now held as an important driver of geographic distributions of island lineages (Matzke 2013a, 2014).

Long-range dispersal events are increasingly recognized as influential mechanisms shaping organismal distributions (e.g., Gillespie et al., 2012; de Queiroz, 2005; Schönhofer et al., 2013; Toussaint et al. 2016). One particular process in this context is founder-event speciation (Carson, 1983; Gillespie \& Roderick, 2002; Paulay \& Meyer, 2002). Matzke (2014) pioneered the inclusion of FEJD into the widely used DEC model (Ree \& Smith, 2008; Ree et al., 2005), thereby demonstrating the positive effects of representing FEJD on estimations of ancestral ranges in island lineages. The "DEC $+J$ " model (Matzke 2014) introduces the free parameter $j$ (jump) for FEJD, where at the time of cladogenesis one daughter lineage inherits the ancestral range, and the other lineage "jumps" to a new area via founder-event speciation (e.g., $\mathrm{A} \rightarrow \mathrm{A}, \mathrm{C}$; or $\mathrm{AB} \rightarrow \mathrm{AB}, \mathrm{C}$ ). We purposefully restrict the application of the term founder-event speciation to this particular biogeographic range-inheritance scenario, as specified in Matzke (2013a). We thereby wish to avoid confusing the term with meanings related to genetic mechanisms proposed by the theory of founder-effect speciation. The models DEC $+\mathrm{J}$, along with likelihood versions of DIVA and BayArea (i.e., DIVALIKE and BAYAREALIKE), are implemented in the R package BioGeoBEARS (Matzke, 2013b).

We analyze the biogeography history of a large group of Neotropical weevils in the EGC, using a comparative, model-based approach. Members of the EGC are broad-nosed weevils in the subfamily Entiminae, tribe Eustylini (Alonso-Zarazaga \& Lyal, 1999). The largest genus in this complex is Exophthalmus Schoenherr, comprising some 95 species (Morrone, 1999; Peck, 2006). In accordance with Franz (2012), our primary taxonomic antecedent for this study, several other genera - i.e., Chauliopleurus Champion, Compsoricus Franz, Diaprepes Schoenherr, Pachnaeus Schoenherr, Rhinospathe Chevrolat, Tetrabothynus Labram \& Imhoff, and Tropirhinus Schoenherr - are also part of this complex, which contains some 140 named species. Species of the EGC are relatively large-sized (5-32 mm in length) and often spectacularly colored weevils (Fig. 1). As many other entimines, the adults are foliage feeders whereas the larvae live in soil and feed on roots.

Species of the EGC are distributed in both the Caribbean region and the Neotropical mainland. They are especially diverse in the Caribbean, with $\sim 85$ species or $>60 \%$ of the species diversity restricted to that region. The continental species are concentrated in Central America and southern Mexico ( 44 species). Only 12 species or $<9 \%$ are known from South America, and six species are exclusive to that region. The Caribbean species exhibit high levels of single-island endemism. For instance, in Cuba 19/20 recorded species of the genus Exophthalmus are endemic to that island (Peck, 2006), and 15/17 Hispaniolan species are endemic (Morrone, 1999).

We infer the ancestral range evolution of EGC species based on a newly reconstructed, fossil-calibrated molecular phylogeny. The analysis is based on six gene fragments and includes 65 ingroup terminals. Using the model selection function in the $\mathrm{R}$ package BioGeoBEARS, we perform statistical tests to compare the relative fit of three biogeographic models, and specifically assess the impact of modeling FEJD by adding the jump dispersal parameter " $j$ " to each model. This approach allows us to address the following questions of broader relevance. (1) What are the relative contributions of inter-island dispersal and withinisland or in situ diversification in shaping species distributions? (2) How did EGC species come to occupy both continental and island areas? (3) How does the biogeographic estimation of the EGC inform our cumulative understanding of Caribbean biogeography? 


\section{MATERIALS AND METHODS}

\subsection{Taxonomic sampling, specimen identification and digitization}

The ingroup taxon sampling (Supplementary Table S1) includes 65 species of the EGC, representing nine genera as recognized in Alonso-Zarazaga \& Lyal (1999) and Franz (2012). The taxonomically widely sampled outgroup taxa include 25 species, covering several closely allied tribes: Geonemini, Naupactini, Polydrosini, and Tanymecini. We included Geonemini representatives because Franz (2012) recovered a sister relationship between a therein broadly defined Geonemini and the EGC. Ingroup taxa were sampled from all large Greater Antillean islands; i.e. Cuba (U), Jamaica (J), Hispaniola (H), and Puerto Rico (P) - 44 species; the Lesser Antillean (L) islands of Dominica and St. Lucia - six species; and three Central American (C) countries (Panama, Costa Rica, and Nicaragua) - 15 species. Sampling localities for specimens belonging to the EGC are displayed in Fig. 1. The current sampling lacks specimens directly collected from South America. However, based on a published morphological phylogeny (Franz, 2012) and unpublished additional data, we can confidently place at least seven South American species within the Central American clade of EGC (bottom-most clade in Fig. 2). We provide a detailed assessment of the placement of South American EGC species in the Supplementary Methods descriptions. These species are, however, not included in the phylogenetic or biogeographic analyses, due to a lack of molecular data.

A great effort was made to achieve maximally reliable identifications by consulting original descriptions or reference collections, frequently including independent verifications by additional weevil taxonomy experts (R. Anderon and C.W. O'Brien, pers. comm.). Some specimens could not be identified to known species-level names, due to a lack of unambiguous references or (more often) because they represent undescribed species. To address concerns regarding our recognition of species as expressed by one reviewer, we performed a DNA-based species delimitation analysis using the Bayesian Poisson Tree Process (bPTP) model through an on-line server (http://species.h-its.org/ptp/) (Zhang et al., 2013). Details of this analysis are provided in Supplementary Methods descriptions. We reexamined select specimens whose species membership assignments had conflicting morphology and DNA-based results.

Full, Darwin Core standard-compliant data of DNA-extracted specimens are openly accessible through the Symbiota Collections of Arthropods Network (SCAN: http://symbiota4.acis.ufl.edu/scan/portal/index.php; see Gries et al., 2014) by looking up specimen catalogue numbers (e.g., ASUHIC0033679; listed in Supplementary Table S1). DNA-extracted voucher specimens or conspecifics from identical collecting events were photographed with a Visionary Digital ${ }^{\mathrm{TM}}$ Passport II system, and the images are made available through SCAN.

\subsection{Molecular methods}

DNA extractions were performed using the Qiagen DNeasy® Blood and Tissue Kit (Qiagen). The right hind leg was excised from a specimen and extracted. Six mitochondrial, nuclear, protein-coding or ribosomal gene fragments - Cytochrome c Oxidase subunit I (COI), Cytochrome c Oxidase subunit II (COII), 12s, Arginine Kinase (AK), Elongation Factor 1-

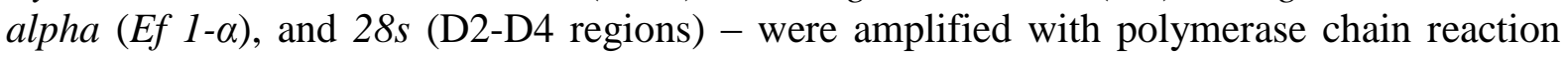
using EmeraldAmp MAX PCR Master Mix in an Eppendorf vapo protect thermal cycler. Primer and PCR programming information is specified in Supplementary Table S2. DNA Sequencing was performed at the Arizona State University DNA Laboratory on an Applied Biosystems 3730 capillary sequencer. DNA sequences were edited with the software Geneious R7 and uploaded to Genbank (see Genbank accession numbers in Supplementary Table S3). 


\subsection{Phylogenetic reconstruction and divergence time estimation}

The software program MAFFT (Katoh \& Standley, 2013) was used to align DNA sequences, applying the Auto alignment strategy for protein coding genes (COI, COII, AK and $E f-1 \alpha)$ and L-INS-i for ribosomal genes $(12 s$ and $28 s)$. The aligned, individual gene data sets were concatenated using SequenceMatrix (Vaidya et al., 2011) to generate a comprehensive matrix of 91 terminals and 4747 nucleotide sites. Best data partition schemes and nucleotide substitution models were determined with PartitionFinder (version 1.1.1) (Lanfear et al., 2012), using the Bayesian Information Criterion (BIC), unlinked branch lengths, and the greedy search algorithm. Three partitions and corresponding best substitution models were inferred (see details in Supplementary Methods descriptions).

Phylogenetic reconstruction and divergence time estimations were performed in a Bayesian framework using BEAST (version 1.8.1) (Drummond \& Rambaut, 2007) via the CIPRES on-line portal (www.phylo.org) (Miller, et al. 2010). The BEAST .xml file was created with BEAUTi (version 1.8.1). The concatenated data matrix was imported into BEAUTi, with the three partitions inferred by PartitionFinder. Substitution models were unlinked among partitions, and clock and tree models were linked. A Birth-Death speciation process with a starting tree obtained from an initial BEAST analysis was used to inform the tree prior. An uncorrelated lognormal relaxed clock was used because initial analyses showed that the ucld.stdev values were far greater than zero, meaning that a strict molecular clock model could be inadequate for our data. The Markov chain Monte Carlo (MCMC) search was conducted for 100 million generations, sampling every 10,000 generations. Convergence and stationarity were checked with Tracer (v1.6) (http://tree.bio.ed.ac.uk/software/tracer/), and all parameter estimates had ESS (effective sample size) values greater than 200. The maximum clade credibility (MCC) tree was generated using the TreeAnnotator (v1.8.1), after discarding the first $25 \%$ of the posterior sample of trees as burn-in. The MCC tree was annotated with median ages and 95\% highest posterior density (HPD) intervals for node ages, and visualized with FigTree (v1.4.0) (Rambaut, 2014).

Lognormal prior age distributions were used on three fossil-calibrated nodes, as these are most appropriate for calibrations based on paleontological data (Ho, 2007). We followed best practices recommended by Parham et al. (2012) to perform the fossil calibrations. We determined the phylogenetic placements of fossils based on apomorphic characters proposed in Franz (2012). The fossil specimen with accession number "NMNH/Woodruff \#9768 (National Museum of Natural History, USA)/USNM505319" (Tropirhinus palpebratus Franz \& Zhang, 2016) was used to calibrate the clade "Compsoricus maricao-Tropirhinus sp.GZ50". This fossil possesses at least two synapomorphies of this clade: (1) elytral apices acutely projecting (character 67, state 1 [67-1] in Franz, 2012); and (2) rostrum in lateral profile slightly arched and tumescent in mid region of dorsal surface (9-1 in Franz 2012) (see Franz \& Zhang, 2016). The fossil specimen with accession number "NMNH, Woodruff \#9774/ USNM505325" (Diaprepes anticus Franz \& Zhang, 2016) was used to calibrate the clade "Exophthalmus roseipes-Diaprepes marginicollis". This fossil specimen exhibits three synapomorphic conditions of this clade: (1) a tricarinate rostrum, where the lateral angles of rostrum are distinctly angulate with slight elevation (17-1), (2) scrobe passing over eye (23-0); and (3) pronotum in dorsal profile with small, shallow, densely arranged, irregularly shaped and spaced concavities (45-1). The last specimen with accession number "KU-NHM-ENT DR-888" (The University of Kansas) (Scelianoma compacta Franz \& Zhang, 2016) was determined to be part the clade "Scelianoma elydimorpha-Artipus monae" as shown in Figure 2 in Franz (2012) based on these characters: (1) hindwings absent (humeri greatly reduced) (83-1); (2) scrobe passing over eye (23-0); and (3) occipital sutures anteriorly extending to subapex of rostrum, anteriorly ascending and visible in lateral profile (26-1). In the current analysis, S. elydimorpha and A. monae did not form a clade. According to the 
reconciliation method proposed by Parham et al. (2012) (see Figure 2 therein), this fossil can be used to calibrate nodes leading to (1) either of these species or (2) the most recent common ancestor of a clade including both species. Because we lack further evidence to determine with which of these (Artipus or Scelianoma) the fossil should be placed with for calibration, we opted to go with the second (common ancestor) option. The clade containing both $S$. elydimorpha and A. monae is the "Entiminae sp.GZ34-Entiminae sp. 6" clade. All three amber fossils are from Dominican Republic and were determined to be from the Early Miocene (Burdigalian, 16-20 Ma) (Franz \& Zhang 2016).

The prior parameters of the lognormal distributions of the clade ages are specified as follows. The offset, mean and standard deviation of the lognormal distributions were set so that the $95 \%$ interval (2.5\% to $97.5 \%$ quantiles) correspond to the minimum ages of the fossils and soft maximum bounds that are reasonably larger than the possible maximum age of the fossils. The calibration based on the KU fossil (KU-NHM-ENT DR-888) for the "Entiminae sp.GZ34-Entiminae sp. 6" clade was given a lognormal prior (in Myr) of $\log ($ Mean $)=1.8, \log ($ Stdev $)=1.5$ and offset $=15.7,(2.5-97.5 \%$ quantiles $=16.0-130.1)$. The clade "Compsoricus maricao-Tropirhinus sp.GZ50" was set have $\log ($ Mean $)=1.8, \log ($ Stdev $)$ $=1.3$ and offset $=15.5(2.5-97.5 \%$ quantiles $=16.0-92.8)$, based on the NMNH fossil Woodruff \#9768. The "Exophthalmus roseipes-Diaprepes marginicollis" clade was given $\log ($ Mean $)=2.82, \log ($ Stdev $)=0.5$, and offset $=9.7(2.5-97.5 \%$ quantiles $=16.0-54.4)$ based on NMNH the fossil Woodruff \#9774.

In response to a reviewer's comments, we briefly discuss the setting of maximum bounds of the age priors, starting with the setting of prior densities and then more generally. To begin, the date distribution on a fossil specimen is not identical to the date calibration applied to a node based on that fossil. Instead, the date calibration combines the actual fossil date distribution with additional information; i.e., how deep the fossil is likely to be within a living clade, other information about sampling within the corresponding fossil group, and generic background information regarding the evolutionary history of the clade. Imagine we found a great ape fossil in a $16 \mathrm{Ma}$ deposit, and in the same deposit we found a fossil dinosaur that had somehow survived the K-Pg extinction. Our interpretation of the fossil specimen dates would be the same, but they would imply much different things about the molecular date calibrations for crown great apes - which various evidence suggests are only tens of millions of years old - versus crown archosaurs, the presumed common ancestor of bird/dinosaurs and crocodiles, which is much older. Mixing these kinds of information together in the form of a node-date calibration is admittedly pragmatic, but remains common practice for lack of a better option.

In the present study, the three corresponding nodes have different prior density values because they occupy different positions in the phylogenetic reconstruction. The maximum bound of the lognormal age prior distribution of the first and "deepest" calibrated node, the "Entiminae sp.GZ34-Entiminae sp. 6" clade (containing most outgroup taxa), was set to 130.1 Ma. This clade contains both continental (Central American) and Caribbean species, and hence a large (or higher/deeper) value was chosen. McKenna et al. (2009) estimate the age of Curculionidae (all "true weevils") at about 130.2 Ma. The herein sampled clade represents a much less inclusive group of weevils, and accordingly its maximum age would not be more than $130 \mathrm{Ma}$ (but see McKenna 2015 for a younger age estimate of $\sim 90 \mathrm{Ma}$ for the Curculionidae). This clade is the sister to all ingroup taxa, which include the other two clades with fossil calibrations, and hence the former has the largest maximum bound value.

The second calibrated clade "Compsoricus maricao-Tropirhinus sp.GZ50" has a maximum age of 92.8 Ma. This age corresponds to the estimated geologic age of the ProAntillean arc, which broke off from Neotropical mainland in the Late Cretaceous (95-65 Ma). Greater Antillean taxa are unlikely to have an age older than that. The clade is the sister to all 
remaining ingroup taxa - within which the third calibrated node is nested - and therefore the former clade's maximum bound value is larger. Arguably, using a geologic event to calibrate a node can be circular (Sauquet, 2013). However, in our analysis, the geologic event was used only to inform the maximum bound of the prior, which had to be adequately large so as not to be overly informative (i.e., constraining). Thus circularity is not a concern here.

The last calibrated node is "Exophthalmus roseipes-Diaprepes marginicollis", with a. maximum bound set to $54.4 \mathrm{Ma}$. The species in this clade are from Puerto Rico and the Lesser Antilles. The faunas of these regions are unlikely to be older than $55 \mathrm{Ma}$. The degree to which Lesser Antilles have been emergent (above water) during the history of the island arc remains poorly known, but the oldest strata in the southern Lesser Antilles are from the middle Eocene (48-38 Ma) (Hedges, 1996).

The above methods are necessarily pragmatic because there is no single, universally accepted way of setting the parameters for fossil calibration priors. According to Ho and Phillips (2009: 372), "[i]t can be difficult to select objectively a value for the mode of the lognormal distribution." Warnock et al. (2012: 156) assert that "justification is rarely provided for calibration densities or their parameters, despite precautionary examples." While there are some new improved methods for developing node-calibration densities, these require information about the rate of sampling fossils through time. This is not feasible when only rare amber inclusions are available.

Table 1 provides an overview of published best practices and justifications for setting the maximum bounds of age priors. All corresponding fossils used for node calibration are preserved in Dominican ambers. We only include studies that reporting maximum bound values. Among the seven sampled studies, the maximum bounds of nodes calibrated with Dominican amber fossils have values ranging from 21.99 to $77 \mathrm{Ma}$. These studies provide different justifications for these values, or none at all. Overall, we found six different maximum bound values given to Dominican amber fossil, which presumably have very similar geologic ages. This mini-review reveals that a consensus regarding the maximum bounds of age priors is still wanting.

We performed additional analyses with the clock models unlinked for the three partitions or used exponential age priors. Altogether four different analyses were performed (Table 2). Early Miocene (Burdigalian; 16-21 Ma) Dominican amber fossils loaned from the University of Kansas (KU-NHM-ENT DR-888, and the National Museum of Natural History (NMNH accession numbers: Woodruff \#9768/USNM505319 and Woodruff \#9774/ USNM505325) were used for calibrations. We have described and named these taxa, but their formal publication remains pending (Franz \& Zhang, 2016, in review). Phylogenetic placements for these fossils were inferred by coding 88/143 morphological characters for the matrix published in Franz (2012), and then running a parsimony analysis of the expanded matrix. Details are provided in Supplementary Methods descriptions. We apply crowncalibrations because the fossils are assigned to their respective clades based on the shared presence of multiple synapomorphic characters (Franz \& Zhang, 2016, in review). The maximum bounds of the age priors were set to be large enough so that it is highly unlikely for nodes to have divergence dates larger (older) the specified values. However, the time lag between the speciation event and the appearance of the fossil is hard to assess with certainty in such calibrations; and typically, prior densities that are not overly informative are preferred (Heath, 2012).

Central American species of EGC were split into two clades in initial phylogenetic analyses. A small group of three Central American species clustered with an Antillean clade, supported with a low posterior probability value of 50 (Supplementary Fig. S8). This result was incongruent with Franz (2012), who recovered the monophyly of Central American species based on two morphological synapomorphies. To explore the conflict, we conducted 
a maximum likelihood reconstruction using RAxML that also recovered a monophyletic Central American clade (Supplementary Fig. S9), and therefore constrained the monophyly of Central American species in subsequent analyses.

\subsection{Historical biogeographic inferences and model selection}

We recognize and code seven areas corresponding to Caribbean islands or larger Neotropical mainland regions: Cuba, Jamaica, Hispaniola, Puerto Rico (including the British Virgin Islands), Lesser Antilles (herein represented by Dominica and St. Lucia), Central America, and South America. Species distributions are based mainly on our collecting data, but literature records were also used where available (Morrone, 1999; Peck, 2006). Biogeographic inferences were performed with the $\mathrm{R}$ package BioGeoBEARS, which implements DEC, DIVALIKE and BAYAREALIKE. The models have two free parameters, $d$ and $e$, specifying the rate of "dispersal" (range expansion) and "extinction" (range contraction) along the internal branches of a given phylogeny. They also allow specification of a set of biogeographic processes or scenarios (Matzke, 2013a: 243). BioGeoBEARS permits explicit representation of FEJD in the aforementioned models. The additional parameter $j$ is written in lower case, and specifically denotes the parameter versus the process "jump dispersal", which is denoted as "J". The FEJD parameter can be switched on or off. Hence BioGeoBEARS can implement six specific models: DEC, DEC+J, DIVALIKE, DIVALIKE+J, BAYAREALIKE and BAYAREALIKE+J.

To test for effects of modeling FEJD, analyses were performed with and without $\mathrm{J}$. The value of $j$ was not pre-determined, but instead was estimated anew for each analysis. Likelihood ratio tests and the Akaike Information Criterion (AIC) were used to assess the statistical significance of data-to-model fit. When nested models differ by one parameter, a statistically significant increase is indicated by approximately two or more log-likelihood units of difference in the data likelihood. The P-value was also calculated to assess whether the null model, without jump dispersal J, can be rejected. The AIC weights reflect the relative support that the data lend to the model with or without J. Similarly, separate analyses were performed under each model configuration to evaluate the relative suitability of biogeographic processes modeled in DEC, DIVALIKE, and BAYAREALIKE.

We furthermore assessed the effect of imposing dispersal multipliers on the dispersal processes. The first (M0) allows transitions between any areas at any times (i.e., no constraint). The second (M1) applies a dispersal multiplier to model the effect of water currents on dispersal. The prevailing water currents in the Caribbean have followed a southeast-to-northwest direction throughout the Cenozoic (Hedges, 2001). We therefore assigned a smaller transition rate (0.5) to dispersal events in a direction against the prevailing water currents (e.g., from Cuba east to Hispaniola), and a larger value (1) to those directionally aligned with water currents (e.g., from Puerto Rico west to Hispaniola) (Table 3).

To assess the proportions of inter-island dispersal and in situ diversification, we counted the types of biogeographic events inferred based on the most probable ancestral ranges at the internal nodes of the ingroup taxa. We distinguish between the terms "interisland dispersal" and "FEJD"; the former refers to the biogeographic event inferred from an estimation, whereas the latter refers specifically to a biogeographic process built into models. FEJD can take place between two islands, but also between an island and a continent. In biogeographic estimations using models without FEJD, it is also possible to infer inter-island dispersal events, which can only be anagenetic (Ree \& Smith, 2008). 


\section{RESULTS}

\subsection{Phylogenetic relationships, divergence time estimates and species delimitation}

In the MCC phylogeny (Fig. 2), the following genera constitute a monophyletic clade: Compsoricus, Diaprepes, Exophthalmus, Pachnaeus, Rhinospathe, Tetrabothynus, and Tropirhinus. Jointly these entities correspond to the EGC in the current sense. Exophthalmus in the broad sense (e.g., Morrone, 1999) is polyphyletic. The Eustylini in the sense of AlonsoZarazaga \& Lyal (1999) are polyphyletic and comprise three clades, including the EGC and two additional lineages, i.e., Scelianoma Franz \& Girón and clade comprising "Compsus sp.GZ134 to Xestogaster sp.1".

Within the EGC, species assemblages represented on each island are not monophyletic. For instance, species inhabiting Cuba pertain to six distinct lineages, and species occurring on Hispaniola or Puerto Rico are derived from five separate lineages. The four endemic Jamaican species form a paraphyletic grade relative to an exclusive Cuban clade. In the MCC phylogeny where the monophyly of Central American species is not constrained, a clade containing Cuban and Hispaniolan species is nested within an otherwise exclusively Central American radiation, rendering the latter paraphyletic (Supplementary Fig. S8). This nested Caribbean group "Exophthalmus cinerascens to Exophthalmus pictus fulvovirgatus" is recovered as sister to a small clade including three Central American species; however, their relationship has a low posterior probability of $50.0 \%$. When the monophyly of the Central American species is constrained, the same Caribbean clade is inferred as sister to an exclusively Central American clade (Fig. 2).

The age estimates based on the analysis with an uncorrelated lognormal relaxed clock, linked clocked models, and lognormal age prior distributions are specified in Table 2 (analysis \#1). Additional analyses showed similar age estimates for the EGC and fossilcalibrated notes, with the median ages varying from 0.58 to $4.70 \mathrm{Myr}$ and the 95\% HDP intervals largely overlapping (Table 2). The inferred divergence dates indicate that the diversification of the EGC began in the late Oligocene (24.6 Ma, 95\% HPD: 18.0-33.4). Two daughter clades diverged within the next 1.5-4.3 Myr, during the early Miocene. The Central American clade split from its sister Caribbean lineage in the early Miocene (18.1 Ma, 95\% HPD: 13.2-24.7), approximately 6.5 Myr after the time of origin of the EGC.

In the best supported bPTP maximum likelihood (ML) or Bayesian analyses, 54 or 53 species of the EGC were recovered, 11 or 12 less than the number (65) of species delimited based on morphology. Nine (ML) or eight (Bayesian) groups of "species complexes" - clades with short internal branches - consisted of two or more morphology-based species. The likelihood reconstruction is shown in Fig. S7. In light of this discrepancy, we re-examined the pertinent specimens for their morphological characters and were able to re-affirm distinct species identities for most of the pre-differentiated specimen sets. The three groups for which the initial morphological species delimitation may have caused incorrect splitting are (1) Pachnaeus sp. GZ52 and GZ53, (2) Pachnaeus sp. GZ24, GZ6 and GZ26, and (3) Exophthalmus pictus and E. pictus fulvovirgatus. However, an alternative, less granular grouping scheme will not impact biogeographic inferences, because the morpho-species within each of the molecular complexes consistently occur in the same geographic area.

\subsection{Biogeographic history of the EGC}

The biogeographic model DIVALIKE+J, with the M1 model constraint applied, yields the highest likelihood of the data among all tested models, based on the chronogram with a monophyletic Central American clade (log likelihood: $\mathrm{LnL}=-115.39$; parameter estimates: $d=0, e=0$ and $j=0.06$ ) (Table 4). In contrast, biogeographic estimations based on phylogenies that have a paraphyletic Central American grade have consistently lower log likelihood values, regardless of the model or constraint used (Table S4. The best estimation is 
shown in Supplementary Fig. S10). These estimations are therefore not preferred. Hence, the biogeographic reconstructions with a monophyletic Central American scenario will be the basis for discussing of the biogeographic history of the EGC and model comparisons. According to the best-fitting model, the ancestor of the EGC occupied Puerto Rico in the Early Miocene (24.6 Ma, Fig. 3a). One of the clade's two descendant lineages inherited Puerto Rico as its most probable ancestral range, whereas the other lineage colonized Cuba via FEJD.

The biogeographic history of the Caribbean species is largely characterized by withinisland in situ diversification, accompanied by relatively infrequent inter-island dispersals. A total of 16 FEJD events $(25.0 \%)$ are estimated to have occurred along the 64 internal nodes in the complex, with diversification periods ranging from 24.6 to 9.2 Ma. No dispersal events occurred after 9.2 Ma (Fig. 3). In situ diversification is inferred for 47 of the remaining nodes (73.4\%). Estimates for one node - rooting the clade "Tropirhinus sp.38 to Tropirhinus sp.GZ50" and its immediate descendants - are ambiguous. The scenario of $\mathrm{U} \rightarrow \mathrm{H}, \mathrm{P}$ was plotted for that node and its two corners (Fig. 3). This scenario does not necessarily suggest a biogeographic event where the ancestral species occupying Cuba simultaneously colonized Hispaniola and Puerto Rico and disappeared from Cuba. The result merely reflects a summary of the most likely range at each of three points. The corresponding node was not included in the calculation of biogeographic events. Colonization of Central America took place $18.8 \mathrm{Ma}$, mediated via jump dispersal from an ancestor lineage that most likely occupied Hispaniola. This event led to a subsequent radiation in Central America that is linked to the origin of $>40$ continental species.

The reconstructed distributions, and directions and frequencies of inter-island colonization events, are shown in Fig. 3. Accordingly, Hispaniola and Puerto Rico were major source islands of colonists, accounting for 12/16 (75.0\%) of out-of-island emigration events. Cuba acted as a "sink" for colonists seven times, Hispaniola four times, and Puerto Rico twice. Jamaica and the Lesser Antilles each acted once as a source or sink. Inter-island dispersal between the Lesser Antilles and the Greater Antilles was limited to Puerto Rico.

\subsection{Model comparison and impact of FEJD}

Representing FEJD strongly influences our analyses. Without this model parameter, biogeographic estimations based on the three biogeographic models - DEC, DIVALIKE, and BAYAREALIKE - show mixed signals. The ancestral range estimations are identical at nearly all nodes with an age less than $15 \mathrm{Ma}$ (Fig. 4). These nodes involve mainly within-area diversification or sympatric range-inheritance. Between-model differences are evident mainly at deeper bifurcations. According to the DIVALIKE and BAYAREALIKE estimations, the most probable ancestral range of the EGC is " $\mathrm{P}+\mathrm{H}+\mathrm{U}$ " (Fig. 4a,c), i.e., widespread in three Greater Antillean islands. The DEC model infers " $\mathrm{P}+\mathrm{H}+\mathrm{U}+\mathrm{C}$ ", thereby adding Central America to the ancestral range (Fig. 4b). Scenarios inferred at the intermediate nodes differ more dramatically between models. For example, in the DIVALIKE analysis, the two immediate daughter lineages connecting to the deepest node have "P" and " $\mathrm{P}+\mathrm{H}+\mathrm{J}+\mathrm{U}+\mathrm{C}$ " as their ancestral range, in contrast to " $\mathrm{P}+\mathrm{H}+\mathrm{U}$ " and " $\mathrm{P}+\mathrm{H}+\mathrm{U}+\mathrm{C}$ " in $\mathrm{DEC}$, and " $\mathrm{P}+\mathrm{H}+\mathrm{U}$ " and "H+U" in BAYAREALIKE.

Adding FEJD dramatically improves model-to-data fit. The data likelihood values obtained by modeling the jump dispersal parameter $j$ are 45.6-58.2 log-likelihood units higher across analytical methods or model constraints in comparison to those obtained modeling only dispersal and extinction (Table 4). The differences are statistically significant: likelihood-ratio tests for all analyses strongly favor the inclusion of $j$. In comparison, the null model, i.e. the nested model where $j=0$ confers the same likelihood on the data, is always rejected at $\mathrm{P}<0.0001$. In addition, the AIC model weights show decisive support for models 
including FEJD, with exceedingly high AIC weight ratios $(2.39 \mathrm{E}+19-6.72 \mathrm{E}+24)$. Accounting for FEJD also significantly affects parameter estimations: the $j$ parameter is always positive, and the $d$ and $e$ parameters are effectively negligible. Lastly, adding FEJD to the models strongly refines ancestral area inferences. When added, the most likely ancestral areas of all internal nodes within the ingroup are consistently resolved as single areas, whereas widespread ancestral ranges are obtained at 16 nodes in absence of this parameter (Fig. 5a,b).

Application of the M1 model constraint and jump dispersal to the three general models yields similar biogeographic estimates (Fig. 5). Selective application of the M0 model (no constraint) versus the M1 model (favoring dispersals along prevailing water currents) primarily affects the directionality of the dispersals (Fig. 5a,c,f). Overall, these differences are too small to favor one model over another (Table 4; see also Burnham \& Anderson, 2002, p. 78). When no constraint (M0) is applied, the DIVALIKE+J model estimates ten dispersals against the prevailing oceanic water currents, and six following the currents (Fig. 5f). With the M1 constraint activated for the same model, 12 dispersals are directionally aligned with water currents and four are oriented against the currents. Patterns of emigration-immigration also differ: under the M0 constraint Cuba is a major source for colonists, whereas under the M1 constraint the island acts mainly as a sink.

All biogeographic estimations under both model constraints (M0, M1), using six models (DEC, DEC $+\mathrm{J}$, DIVALIKE, DIVALIKE $+\mathrm{J}$, BAYAREALIKE and BAYAREALIKE+J) are shown in Figs. S1-S6 in the Supplementary Data.

\section{DISCUSSION \\ 4.1 Impact of biogeographic models, FEDJ and model constraints}

Our results show a complex, two-tiered pattern of data-to-model fit that demonstrates the importance of testing biogeographic models broadly for the EGC and likely many other Caribbean/Neotropical lineages. Most significantly, accounting for FEJD dramatically increases model fit regardless of the biogeographic method used. In biogeographic estimations with FEJD, additional non-founder dispersals and extinctions are unnecessary for explaining range evolution in the EGC. Dispersal is perfectly correlated with cladogenesis via FEJD. The three " $+\mathrm{J}$ " models produce highly congruent results concerning ancestral ranges, dispersal frequency, and direction (Fig. 5). These results corroborate Matzke's (2014) conclusion that biogeographic models with FEJD best account for island radiations. Our findings underscore the importance of FEJD in shaping the biogeographic history of Caribbean entimine weevils. This study, together with several recent historical biogeographic studies of organisms with a strong presence on oceanic islands (e.g., Berger, et al., 2016; Matos-Maraví et al., 2013; Voelker et al., 2014; Shaw et al., 2015; Tänzler et al., 2016), reveal an emerging pattern: FEJD is a critical process driving the diversification of island organisms.

The second-tier insight is that, without modeling jump dispersal, the choice of biogeographic model (i.e., DEC, DIVA and BayArea) can have a major impact on ancestral range estimations. These contingencies can produce significant differences for inferring the most probable ancestral areas and biogeographic scenarios (Fig. 4). In particular, DEC and DIVALIKE estimates yield higher data likelihoods than BAYAREALIKE (Table 4). Whereas DEC and DIVA allow for different kinds of cladogenetic events, BayArea omits all range-changing cladogenetic processes, instead assuming that all changes in geographic range occur via dispersal and extinction events along branches. However, the relatively lower data likelihoods of the BAYAREALIKE inferences indicate that cladogenesis was an important process in the biogeographic history of Caribbean weevils. Clearly, future studies 
should explore and empirically justify alternative model choices and their effects (robustness) on biogeographic interpretations.

Assigning higher transition rates to dispersal in the same direction of the prevailing water currents in the Caribbean under the model constraint (M1) only marginally improves data likelihoods (Table 4), while allocating highly differential roles to Cuba and Hispaniola (Fig. 5a,c,f). Under the M0 model constraint, Cuba functions primarily as a source of colonists, providing emigrants to Puerto Rico, Hispaniola and Jamaica. Under that same model, Hispaniola acts as a major sink of colonists. Conversely, the M1 model constraint renders Cuba mainly as a "sink", receiving colonists or immigrants, and Hispaniola acts predominantly a source of colonists. This highlights the importance of water currents in determining the prevailing dispersal direction and warrants future explorations of the impacts of modeling water currents in Caribbean historical biogeography.

\subsection{In situ diversification, inter-island dispersal, and plausibility of the jump dispersal model}

Our findings indicate that in situ diversification has played an essential role in shaping high levels of endemism of Caribbean Exophthalmus species. In situ diversification comprises $\sim 73.4 \%$ of the 64 phylogeny-internal biogeographic events, whereas FEJD accounts for the remaining events $(\sim 25 \%, 16 / 64)$. In situ diversification is recognized as an important driver of species diversity that has been documented for many island lineages (e.g., Bennett \& O'Grady, 2013; Bruyn et al., 2014; Cowie, 1995; Matos-Maraví et al., 2014). High rates of in situ diversification on islands may be due to several factors such as an abundance of open niches on islands (Gillespie et al., 2012), within-island vicariance (Matos-Maraví et al., 2014), environmental and topographic variability (Paulay, 1994), large area size (Losos \& Schluter, 2000), and long emergent history (Bruyn et al., 2014). Several Greater Antillean entimine genera such as Apotomoderes, Apodrosus, and Lachnopus show distinct biogeographic patterns - such as high levels of endemism and apparent within-island diversification - that merit further attention (e.g., Franz, 2010; Girón \& Franz, 2010, 2012).

With regards to the plausibility of Exophthalmus species dispersing across oceanic barriers, we note that several studies of diverse lineages have shown rafting on flotsam as a possible means of long-distance oceanic over-water dispersal (Cheng \& Birch, 1978; Donlan \& Nelson, 2003; Heatwole \& Levins, 1972). In particular, Heatwole \& Levins (1972) found pieces of flotsam with live adult weevils in the waters around the islands of the Puerto Rican bank. Franz et al. (2009) invoked dispersal to explain the distribution of widespread weevil species on the Late Miocence-/Early Pliocene-emergent Mona Island. Over-water oceanic dispersal is also a likely colonization mechanism for weevils of the Galapagos Islands (Peck, 2001; Sequeira et al., 2000), and of the South Indian Ocean Province Islands in the subAntarctic region (Chown, 1994). Many entimine lineages are known to have established in areas outside their native ranges (e.g., O'Brien et al., 2006; Pinski et al., 2005; Woodruff, 1985). Species of the EGC appear to be generalist herbivores (Dixon, 1954), a habit may further promote their capacity for successful colonization.

\subsection{Island-to-continent colonization}

A surprising outcome of our study is the colonization of Central American mainland from the Caribbean (Fig. 3). The most fitting biogeographic estimate (DIVALIKE+J on M1 model constraint) infers a jump dispersal from Hispaniola to Central America at 18.1 Ma (Fig. 3). Until recently it had been held that colonization of islands from continents is unidirectional; however, evidence supporting invasion of continents by island species is emerging (Bellemain \& Ricklefs, 2008). Islands are frequently thought to be easier to invade because island communities have a lower diversity, their ecological spaces are less densely 
packed, and interspecific competition is considered less intense (Bellemain \& Ricklefs, 2008; Nicholson et al., 2005). Conversely, continents harbor more species and hence more potential colonists. Continental populations are presumably selected for increased competitive ability, making colonists more likely to become established on islands. Our reconstructions complicate the picture: the reverse colonization from the Caribbean to Central America has produced widespread, species-rich continental communities in the EGC, suggesting that island species are not fundamentally disadvantaged as colonizing competitors in comparison their continental counterparts.

The continent-to-island pattern narrative may not apply well to the species of the EGC in ancient parts of Central America, which comprise continental areas that have undergone extensive geologic changes in the (recent) Cenozoic past. During the early to middle Miocene ( 20-14 Ma), southern or lower Central America likely constituted a narrow peninsula or chain of islands (Iturralde-Vinent \& MacPhee, 1999; Kirby \& MacFadden, 2005; Kirby et al., 2008). Historical biological communities in these areas may have experienced island-like environments. The invasion of Central America by the Caribbean Exophthalmus weevils may have resembled inter-island dispersal.

\subsection{Implications on Caribbean biogeography}

Our analyses augment the still limited number of model-based inferences focusing on the historical biogeography of Caribbean invertebrates (see Lewis et al., 2015; Matos-Maraví et al., 2014; McHugh et al., 2014; Oneal et al., 2010). In that greater context of understanding diversification in the Caribbean archipelago, our results convey new insights that we discuss in the following.

We may recognize three major Caribbean biogeography hypotheses with relevance to our analysis. First, the vicariance hypothesis specifies that Caribbean biota originated on a proto-Antillean arc once connected to Neotropical continents in the late Cretaceous (95-65 Ma), which subsequently drifted eastwards to its current position (Rosen, 1975, 1985). Second, the dispersal hypothesis proposes that organisms colonized Caribbean islands mainly from South America via oceanic over-water dispersal throughout the Cenozoic (65.5 Ma to present), and through continued dispersal between islands (e.g., Hedges et al., 1992; Heinicke et al., 2007; reviewed in Hedges, 2001 \& 2006). Last, the GAARLandia hypothesis maintains that the Greater Antilles and northern South America were briefly connected by a Greater Antilles + Aves Ridge land span during the Eocene-Oligocene transition (35-33 Ma) (Iturralde-Vinent \& MacPhee, 1999).

Perhaps surprisingly, the over-water dispersal hypothesis best aligns with our preferred biogeographic model reconstruction (i.e., DIVALIKE $+\mathrm{J}$ with the M1 model constraint). Both the vicariance and the GAARLandia hypotheses are more difficult to reconcile with this reconstruction due to incongruences in the timing of diversification. In particular, our inferred scenario of Antillean species colonizing Central America, or of a paraphyletic Caribbean grade, cannot be reconciled with the ancient vicariance hypothesis which predicts sister-group relationships between Central America and Caribbean lineages. Evidence of repeated inter-island jump dispersal events in the Exophthalmus, occurring from 25-10 Ma, poorly aligns with an auxiliary postulate of the GAARLandia hypothesis, i.e., island-to-island vicariance (Iturralde-Vinent \& MacPhee, 1999, p. 52). Indeed, dispersal over oceanic water gaps appears to be a commonly inferred biogeographic process in the recent literature studying various island systems (Balke et al., 2009; Bell et al., 2014; Clayton et al., 2009; Schweizer et al., 2010).

Could our results convincingly reject the ancient vicariance and the GAARlandia hypotheses? That inference would appear to be too strong. Compared to the over-water dispersal hypothesis, the two 'alternatives' make other specific predictions that might be best 
applied to certain lineages whose ages better fit the time windows stated by these hypotheses. Other issues such as uncertainty and errors in molecular dating could also alter our understanding of the timing of divergences of the pertinent taxa. Unaccounted South American species will need to be studied in the future to produce a complete picture of the biogeographic history of the EGC. We echo Hedges (2001) that these hypotheses are not necessarily mutually exclusive of one another. The intricacies of the predictions of the hypotheses need to be teased out in relation to the biogeographic history of the taxa being studied.

\section{CONCLUSION}

Our study sheds new light on the historical biogeography and evolution of a group of weevils constituting a large radiation in the Caribbean archipelago and Neotropical mainland. Given the strong effects of including FEJD and other model parameters, our analysis of highlights a great need for comprehensive model exploration and statistically mediated datato-model fit optimization in support of reliable historical biogeographic inferences. Among other surprising insights related to the timing and mode of evolutionary radiation for this lineage, we have uncovered an island-to-continent colonization event, thereby providing further evidence that islands can be an important source of continental diversity. We show that the endemic diversity of the focal lineages in the Caribbean region is largely the outcome of in situ diversification. Many weevil lineages have diversified extensively on islands or island-like habitats (Girón \& Franz, 2012; Paulay, 1985; Riedel et al., 2014; Samuelson, 2003; Sequeira et al., 2008; Setliff, 2007; Tänzler et al. 2014, Toussaint et al., 2015; Van Dam \& Matzke, 2016), and thus are highly suitable for future research on island evolution and biogeography.

\section{ACKNOWLEDGEMENTS}

We thank Robert Anderson (Canadian Museum of Nature) for contributed specimens and Charles O'Brien (Green Valley, Arizona) for assistance with species identifications. Anyimilehidi Mazo-Vargas and Jennifer Girón assisted with early field work and (AMV only) contributed a portion of the molecular data. Andrew Johnston and Salvatore Anzaldo helped with obtaining images of reference collections. Steven Davis (University of Kansas) and Conrad Labandeira (Smithsonian National Museum of Natural History) arranged fossil loans. William Sides, Lin Pan, and Kevin Wang (Arizona State University; all SOLUR students) photographed specimen. Research support granted by various funding agencies is kindly acknowledged, as follows: National Science Foundation [grants DEB-1155984 (NMF), EF1207371 (NMF), EF-0832858 (NJM), and DBI-1300426 (NJM)]; U.S. Department of Agriculture Agreement [No. 58-1275-1-335 (NMF)]; and U.S. Department of Homeland Security and The University of Tennessee, Knoxville (NJM).

\section{REFERENCES}

Almeida E.A.B., Pie M.R., Brady S.G., \& Danforth B.N. (2012) Biogeography and diversification of colletid bees (Hymenoptera: Colletidae): Emerging patterns from the southern end of the world. Journal of Biogeography, 39, 526-544.

Alonso-Zarazaga M.A. \& Lyal C.H.C. (1999) A World Catalogue of Families and Genera of Curculionoidea (Insecta: Coleoptera) (excepting Scolytidae and Platypodidae). Entomopraxis, Barcelona. 
Balke M., Ribera I., Hendrich L., Miller M.A., Sagata K., Posman A., Vogler A.P., \& Meier R. (2009) New Guinea highland origin of a widespread arthropod supertramp. Proceedings of the Royal Society of London B: Biological Sciences, rspb.2009.0015.

Bell R.C., Drewes R.C., Channing A., Gvoždík V., Kielgast J., Lötters S., Stuart B.L., \& Zamudio K.R. (2014) Overseas dispersal of Hyperolius reed frogs from Central Africa to the oceanic islands of São Tomé and Príncipe. Journal of Biogeography, $\mathbf{4 2}$, $65-75$

Bellemain E. \& Ricklefs R.E. (2008) Are islands the end of the colonization road? Trends in Ecology \& Evolution, 23, 461-468.

Bennett G.M. \& O'Grady P.M. (2013) Historical biogeography and ecological opportunity in the adaptive radiation of native Hawaiian leafhoppers (Cicadellidae: Nesophrosyne). Journal of Biogeography, 40, 1512-1523.

Berger B.A., Kriebel R., Spalink D., \& Sytsma K.J. (2016) Divergence times, historical biogeography, and shifts in speciation rates of Myrtales. Molecular Phylogenetics and Evolution, 95, 116-136.

Boudinot B.E., Probst R.S., Brandão C.R.F., Feitosa R.M., \& Ward P.S. (2016) Out of the Neotropics: Newly discovered relictual species sheds light on the biogeographical history of spider ants (Leptomyrmex, Dolichoderinae, Formicidae). Systematic Entomology, 41, 658-671.

Bourguignon T., \& 207 other authors (2016) Oceanic dispersal, vicariance and human introduction shaped the modern distribution of the termites Reticulitermes, Heterotermes and Coptotermes. Proceedings of the Royal Society of London B: Biological Sciences, 283, 20160179.

Bruyn M. de, Stelbrink B., Morley R.J., Hall R., Carvalho G.R., Cannon C.H., van den Bergh G., Meijaard E., Metcalfe I., Boitani L., Maiorano L., Shoup R., \& Rintelen T. von (2014) Borneo and Indochina are major evolutionary hotspots for Southeast Asian biodiversity. Systematic Biology, 63, 879-901.

Burnham K.P. \& Anderson D.R. (2002) Model selection and multimodel inference: $a$ practical information-theoretic approach. Springer Science \& Business Media,

Carson H.L. (1983) Chromosomal sequences and interisland colonizations in Hawaiian Drosophila. Genetics, 103, 465-482.

Cheng L. \& Birch M.C. (1978) Insect flotsam: an unstudied marine resource. Ecological Entomology, 3, 87-97.

Chown S.L. (1994) Historical ecology of sub-Antarctic weevils (Coleoptera: Curculionidae): patterns and processes on isolated islands. Journal of Natural History, 28, 411-433.

Clayton J.W., Soltis P.S., \& Soltis D.E. (2009) Recent Long-Distance Dispersal Overshadows Ancient Biogeographical Patterns in a Pantropical Angiosperm Family (Simaroubaceae, Sapindales). Systematic Biology, 58, 395-410.

Cowie R.H. (1995) Variation in species diversity and shell shape in Hawaiian land snails: In situ speciation and ecological relationships. Evolution, 49, 1191-1202.

Dixon W.B. (1954) Fiddler beetles. Natural History Notes, Natural History Society of Jamaica, 69, 157-183.

Donlan C.J. \& Nelson P.A. (2003) Observations of invertebrate colonized flotsam in the eastern tropical Pacific, with a discussion of rafting. Bulletin of Marine Science, $\mathbf{7 2}$, 231-240.

Drummond A.J. \& Rambaut A. (2007) BEAST: Bayesian evolutionary analysis by sampling trees. BMC Evolutionary Biology, 7, 214.

Franz N. (2010) Revision and phylogeny of the Caribbean weevil genus Apotomoderes Dejean, 1834 (Coleoptera, Curculionidae, Entiminae). ZooKeys, 49, 33-75. 
Franz N.M. (2012) Phylogenetic reassessment of the Exophthalmus genus complex (Curculionidae: Entiminae: Eustylini, Geonemini). Zoological Journal of the Linnean Society, 164, 510-557.

Franz N.M., O’Brien C.W., \& Nunez D.R. (2009) New records of weevils (Coleoptera: Curculionoidea) from Mona Island, Puerto Rico. Solenodon, 8, 82-98.

Franz N. \& Zhang G. (2016) Three new species of entimine weevils in Early Miocene amber from the Dominican Republic (Coleoptera: Curculionidae). Biodiversity Data Journal, (in press).

Gillespie R.G., Baldwin B.G., Waters J.M., Fraser C.I., Nikula R., \& Roderick G.K. (2012) Long-distance dispersal: a framework for hypothesis testing. Trends in Ecology \& Evolution, 27, 47-56.

Gillespie R.G. \& Roderick G.K. (2002) Arthropods on islands: colonization, speciation, and conservation. Annual Review of Entomology, 47, 595-632.

Girón J.C. \& Franz N.M. (2010) Revision, phylogeny and historical biogeography of the genus Apodrosus Marshall, 1922 (Coleoptera: Curculionidae: Entiminae). Insect Systematics \& Evolution, 41, 339-414.

Girón J.C. \& Franz N.M. (2012) Phylogenetic assessment of the Caribbean weevil genus Lachnopus Schoenherr (Coleoptera: Curculionidae: Entiminae). Invertebrate Systematics, 26, 67-82.

Goldman N. (1993) Statistical tests of models of DNA substitution. Journal of Molecular Evolution, 36, 182-198.

Gries C., Gilbert E., \& Franz N. (2014) Symbiota - A virtual platform for creating voucherbased biodiversity information communities. Biodiversity Data Journal, 2, e1114.

Hansen T.F. (1997) Stabilizing Selection and the Comparative Analysis of Adaptation. Evolution, 51, 1341-1351.

Heath TA, Holder MT, Huelsenbeck JP. (2012) A Dirichlet process prior for estimating lineage-specific substitution rates. Molecular Biology and Evolution. 29, 939-255.

Heatwole H. \& Levins R. (1972) Biogeography of the Puerto Rican Bank: flotsam transport of terrestrial animals. Ecology, 53, 112-117.

Hedges S.B. (2001) Biogeography of the West Indies: an overview. Biogeography of the West Indies: Patterns and Perspectives (ed. by C.A. Woods and F.E. Sergile), CRC Press,

Hedges S.B. (2006) Paleogeography of the Antilles and origin of West Indian terrestrial vertebrates. Annals of the Missouri Botanical Garden, 93, 231-244.

Hedges S.B., Hass C.A., \& Maxson L.R. (1992) Caribbean biogeography: molecular evidence for dispersal in West Indian terrestrial vertebrates. Proceedings of the National Academy of Sciences of the United States of America, 89, 1909-1913.

Heinicke M.P., Duellman W.E., \& Hedges S.B. (2007) Major Caribbean and Central American frog faunas originated by ancient oceanic dispersal. Proceedings of the National Academy of Sciences, 104, 10092-10097.

Ho S.Y.M. (2007) Calibrating molecular estimates of substitution rates and divergence times in birds. Journal of Avian Biology, 38, 409-414.

Ho S.Y.W., \& Phillips, M.J. (2009) Accounting for calibration uncertainty in phylogenetic estimation of evolutionary divergence times. Systematic Biology, 58, 367-380.

Hipsley C.A., Himmelmann L., Metzler D., \& Müller J. (2009) Integration of Bayesian molecular clock methods and fossil-based soft bounds reveals early Cenozoic origin of African lacertid lizards. BMC Evolutionary Biology, 9, 151.

Iturralde-Vinent M. \& MacPhee R.D.E. (1999) Paleogeography of the Caribbean region: implications for Cenozoic biogeography. Bulletin of the American Museum of Natural History, 238, 3-95. 
Katoh K. \& Standley D.M. (2013) MAFFT multiple sequence alignment software version 7: improvements in performance and usability. Molecular Biology and Evolution, 30, $772-780$.

Landis M.J., Matzke N.J., Moore B.R., \& Huelsenbeck J.P. (2013) Bayesian Analysis of Biogeography when the Number of Areas is Large. Systematic Biology, 62, 789-804.

Lanfear R., Calcott B., Ho S.Y.W., \& Guindon S. (2012) PartitionFinder: Combined selection of partitioning schemes and substitution models for phylogenetic analyses. Molecular Biology and Evolution, 29, 1695-1701.

Kirby M.X., Jones D.S., \& MacFadden B.J. (2008) Lower Miocene stratigraphy along the panama canal and its bearing on the Central American peninsula. PLoS ONE, 3, e2791.

Kirby M.X. \& MacFadden B. (2005) Was southern Central America an archipelago or a peninsula in the middle Miocene? A test using land-mammal body size. Palaeogeography, Palaeoclimatology, Palaeoecology, 228, 193-202.

Lewis D.S., Sperling F.A.H., Nakahara S., Cotton A.M., Kawahara A.Y., \& Condamine F.L. (2015) Role of Caribbean Islands in the diversification and biogeography of Neotropical Heraclides swallowtails. Cladistics, 31, 291-314.

Losos J.B. \& Schluter D. (2000) Analysis of an evolutionary species-area relationship. Nature, 408, 847-850.

Matos-Maraví P., Águila R.N., Peña C., Miller J.Y., Sourakov A., \& Wahlberg N. (2014) Causes of endemic radiation in the Caribbean: evidence from the historical biogeography and diversification of the butterfly genus Calisto (Nymphalidae: Satyrinae: Satyrini). BMC Evolutionary Biology, 14, 199.

Matzke N.J. (2013a) Probabilistic historical biogeography: new models for founder-event speciation, imperfect detection, and fossils allow improved accuracy and modeltesting. Frontiers of Biogeography, 5, 242-248.

Matzke, N.J. (2013b) BioGeoBEARS: BioGeography with Bayesian (and Likelihood) Evolutionary Analysis in R Scripts. R package, version 0.2.1, published July 27, 2013 at: http://CRAN.R-project.org/package=BioGeoBEARS.

Matzke N.J. (2014) Model selection in historical biogeography reveals that founder-event speciation is a crucial process in island clades. Systematic Biology, 63, 951-970.

McHugh A., Yablonsky C., Binford G., \& Agnarsson I. (2014) Molecular phylogenetics of Caribbean Micrathena (Araneae: Araneidae) suggests multiple colonisation events and single island endemism. Invertebrate Systematics, 28, 337-349.

McKenna D.D., Sequeira A.S., Marvaldi A.E., \& Farrell B.D. (2009) Temporal lags and overlap in the diversification of weevils and flowering plants. Proceedings of the National Academy of Sciences, 106, 7083-7088.

Mckenna, D. D., Wild, A. L., Kanda, K., Bellamy, C. L., Beutel, R. G., Caterino, M. S., ...

Farrell, B. D. (2015). The beetle tree of life reveals that Coleoptera survived end-

Permian mass extinction to diversify during the Cretaceous terrestrial revolution.

Systematic Entomology, 40, 835-880.

Miller M.A., Pfeiffer W., and Schwartz T. (2010) Creating the CIPRES Science Gateway for inference of large phylogenetic trees. Proceedings of the Gateway Computing Environments Workshop (GCE), 14 Nov. 2010, New Orleans, LA pp 1 - 8.

Morrone J.J. (1999) The species of Entiminae (Coleoptera: Curculionidae) ranged in America south of the United States. Anales del Instituto de Biología de la UNAM, serie Zoología, 70, 99-168.

Nicholson K.E., Glor R.E., Kolbe J.J., Larson A., Blair Hedges S., \& Losos J.B. (2005) Mainland colonization by island lizards. Journal of Biogeography, 32, 929-938. 
O’Brien C.W., Haseeb M., \& Thomas M.C. (2006) Myllocerus undecimpustulatus undatus Marshall (Coleoptera: Curculionidae), a recently discovered pest weevil from the Indian subcontinent. Entomology Circular, 412, 1-4.

O'Meara B.C. (2012) Evolutionary Inferences from Phylogenies: A Review of Methods. Annual Review of Ecology, Evolution, and Systematics, 43, 267-285.

Oneal E., Otte D., \& Knowles L.L. (2010) Testing for biogeographic mechanisms promoting divergence in Caribbean crickets (genus Amphiacusta). Journal of Biogeography, 37, $530-540$.

Parham J.F., Donoghue P.C.J., Bell C.J., Calway T.D., Head J.J., Holroyd P.A., Inoue J.G., Irmis R.B., Joyce W.G., Ksepka D.T., Patané J.S.L., Smith N.D., Tarver J.E., Tuinen M. van, Yang Z., Angielczyk K.D., Greenwood J.M., Hipsley C.A., Jacobs L., Makovicky P.J., Müller J., Smith K.T., Theodor J.M., Warnock R.C.M., \& Benton M.J. (2012) Best Practices for Justifying Fossil Calibrations. Systematic Biology, 61, 346-359.

Paulay G. (1985) Adaptive radiation on an isolated oceanic island: the Cryptorhynchinae (Curculionidae) of Rapa revisited. Biological Journal of the Linnean Society, 26, 95187.

Paulay G. (1994) Biodiversity on oceanic islands: its origin and extinction. American Zoologist, 34, 134-144.

Paulay G. \& Meyer C. (2002) Diversification in the tropical pacific: comparisons between marine and terrestrial systems and the importance of founder speciation. Integrative and Comparative Biology, 42, 922-934.

Peck S.B. (2006) A checklist of the beetles of Cuba with data on distributions and bionomics (Insecta: Coleoptera). Arthropods of Florida and Neighboring Land Areas, 18, 1-241.

Pinski R.A., Mattson W.J., \& Raffa K.F. (2005) Composition and seasonal phenology of a nonindigenous root-feeding weevil (Coleoptera: Curculionidae) complex in northern hardwood forests in the Great Lakes region. Environmental Entomology, 34, 298-307.

Planas E. \& Ribera C. (2014) Uncovering overlooked island diversity: Colonization and diversification of the medically important spider genus Loxosceles (Arachnida: Sicariidae) on the Canary Islands. Journal of Biogeography, 41, 1255-1266.

Posada D. \& Crandall K.A. (1998) MODELTEST: testing the model of DNA substitution. Bioinformatics, 14, 817-818.

Price S.L., Powell S., Kronauer D.J.C., Tran L.A.P., Pierce N.E., \& Wayne R.K. (2014) Renewed diversification is associated with new ecological opportunity in the Neotropical turtle ants. Journal of Evolutionary Biology, 27, 242-258.

de Queiroz A. de (2005) The resurrection of oceanic dispersal in historical biogeography. Trends in Ecology \& Evolution, 20, 68-73.

Rambaut A. FigTree, http://tree.bio.ed.ac.uk/software/figtree/, accessed on Oct 01, 2014

Ree R.H., Moore B.R., Webb C.O., \& Donoghue M.J. (2005) A likelihood framework for inferring the evolution of geographic range on phylogenetic trees. Evolution, 59, 2299-2311.

Ree R.H. \& Smith S.A. (2008) Maximum likelihood inference of geographic range evolution by dispersal, local extinction, and cladogenesis. Systematic Biology, 57, 4-14.

Riedel A., Tänzler R., Balke M., Rahmadi C., \& Suhardjono Y.R. (2014) Ninety-eight new species of Trigonopterus weevils from Sundaland and the Lesser Sunda Islands. ZooKeys, 467, 1-162.

Ronquist F. (1997) Dispersal-vicariance analysis: A new approach to the quantification of historical biogeography. Systematic Biology, 46, 195-203.

Rosen D.E. (1975) A vicariance model of Caribbean biogeography. Systematic Biology, 24, 431-464. 
Rosen D.E. (1985) Geological hierarchies and biogeographic congruence in the Caribbean. Annals of the Missouri Botanical Garden, 72, 636-659.

Samuelson G.A. (2003) Review of Rhyncogonus of the Hawaiian Islands (Coleoptera: Curculionidae). Bishop Museum Press, Honolulu.

Sauquet, H. (2013) A practical guide to molecular dating. Comptes Rendus - Palevol, 12, $355-367$.

Schweizer M., Seehausen O., Güntert M., \& Hertwig S.T. (2010) The evolutionary diversification of parrots supports a taxon pulse model with multiple trans-oceanic dispersal events and local radiations. Molecular Phylogenetics and Evolution, 54, 984-994.

Sequeira A.S., Lanteri A.A., Scataglini M.A., Confalonieri V.A., \& Farrell B.D. (2000) Are flightless Galapaganus weevils older than the Galápagos Islands they inhabit? Heredity, 85, 20-29.

Sequeira A.S., Lanteri A.A., Albelo L.R., Bhattacharya S., \& Sijapati M. (2008) Colonization history, ecological shifts and diversification in the evolution of endemic Galápagos weevils. Molecular Ecology, 17, 1089-1107.

Setliff G.P. (2007) Annotated checklist of weevils from the Papuan region (Coleoptera, Curculionoidea). Zootaxa, 1536, 1-296.

Shaw A.J., Shaw B., Johnson M.G., Devos N., Stenøien H.K., Flatberg K.I., \& Carter B.E. (2015) Phylogenetic structure and biogeography of the Pacific Rim clade of Sphagnum subgen. Subsecunda: haploid and allodiploid taxa. Biological Journal of the Linnean Society, 116, 295-311.

Schönhofer A.L., McCormack M., Tsurusaki N., Martens J., \& Hedin M. (2013) Molecular phylogeny of the harvestmen genus Sabacon (Arachnida: Opiliones: Dyspnoi) reveals multiple Eocene-Oligocene intercontinental dispersal events in the Holarctic. Molecular Phylogenetics and Evolution, 66, 303-315.

Tänzler R., Toussaint E.F.A., Suhardjono Y.R., Balke M., \& Riedel A. (2014) Multiple transgressions of Wallace's Line explain diversity of flightless Trigonopterus weevils on Bali. Proceedings of the Royal Society of London B: Biological Sciences, 281, 20132528.

Tänzler R., Dam M.H.V., Toussaint E.F.A., Suhardjono Y.R., Balke M., \& Riedel A. (2016) Macroevolution of hyperdiverse flightless beetles reflects the complex geological history of the Sunda Arc. Scientific Reports, 6, 18793.

Toussaint E.F.A., Tänzler R., Rahmadi C., Balke M., \& Riedel A. (2015) Biogeography of Australasian flightless weevils (Curculionidae, Celeuthetini) suggests permeability of Lydekker's and Wallace's Lines. Zoologica Scripta, 44, 632-644.

Toussaint E.F.A., Hendrich L., Hájek J., Michat M.C., Panjaitan R., Short A.E.Z., \& Balke M. (2016) Evolution of Pacific Rim diving beetles sheds light on Amphi-Pacific biogeography. Ecography, online early view. 10.1111/ecog.02195

Vaidya G., Lohman D.J., \& Meier R. (2011) SequenceMatrix: concatenation software for the fast assembly of multi-gene datasets with character set and codon information. Cladistics, 27, 171-180.

Van Dam M.H. \& Matzke N.J. (2016) Evaluating the influence of connectivity and distance on biogeographical patterns in the south-western deserts of North America. Journal of Biogeography, 43, 1514-1532.

Voelker G., Peñalba J.V., Huntley J.W., \& Bowie R.C.K. (2014) Diversification in an AfroAsian songbird clade (Erythropygia-Copsychus) reveals founder-event speciation via trans-oceanic dispersals and a southern to northern colonization pattern in Africa. Molecular Phylogenetics and Evolution, 73, 97-105. 
Ward P.S., Brady S.G., Fisher B.L., \& Schultz T.R. (2010) Phylogeny and biogeography of dolichoderine ants: Effects of data partitioning and relict taxa on historical inference. Systematic Biology, 59, 342-362.

Warnock R.C.M., Yang Z., \& Donoghue P.C.J. (2012) Exploring uncertainty in the calibration of the molecular clock. Biology Letters, 8, 156-159.

Wood H.M., Matzke N.J., Gillespie R.G., \& Griswold C.E. (2013) Treating fossils as terminal taxa in divergence time estimation reveals ancient vicariance patterns in the palpimanoid spiders. Systematic Biology, 62, 264-284.

Woodruff R.E. (1985) Citrus weevils in Florida and the West Indies: Preliminary report on systematics, biology, and distribution (Coleoptera: Curculionidae). The Florida Entomologist, 68, 370-379.

Yu Y., Harris A.J., \& He X. (2010) S-DIVA (Statistical Dispersal-Vicariance Analysis): A tool for inferring biogeographic histories. Molecular Phylogenetics and Evolution, 56, 848-850.Zhang J., Kapli P., Pavlidis P., \& Stamatakis A. (2013) A general species delimitation method with applications to phylogenetic placements. Bioinformatics, 29, 2869-2876.

\section{APPENDIX A. SUPPLEMENTRAY MATERIAL}

Supplementary data associated with article can be found, in the online version, at [URL to be inserted by publisher]

\section{TABLES}

Table 1. Summary of current methods and justifications of setting maximum bounds of age priors based on fossil-calibrations (all studies used Dominican ambers).

\begin{tabular}{|c|c|c|c|c|}
\hline Study & Fossil-calibrated node(s) & $\begin{array}{l}\text { Prior } \\
\text { distrib } \\
\text { ution }\end{array}$ & $\begin{array}{l}\text { Maximum } \\
\text { bound } \\
(\mathrm{Ma})\end{array}$ & Justification \\
\hline$\frac{\text { Almeida et al. }}{(2012)}$ & $\begin{array}{l}\text { Chilicola (bees; } \\
\text { Hymenoptera: Colletidae) }\end{array}$ & $\begin{array}{l}\text { Logno } \\
\text { rmal }\end{array}$ & 45 & None \\
\hline $\begin{array}{ll}\text { Boudinot et } & \text { et } \\
\underline{\text { al. }(2016)} & \end{array}$ & $\begin{array}{l}\text { Leptomyrmex, } \quad \text { Azteca- } \\
\text { Gracilidris } \\
\text { Hymenoptera: }\end{array}$ & $\begin{array}{l}\text { Unspe } \\
\text { cified }\end{array}$ & 70,77 & $\begin{array}{l}\text { Based on a previous } \\
\text { estimate }\end{array}$ \\
\hline$\frac{\text { Bourguignon }}{\text { et al. (2016) }}$ & $\begin{array}{ll}\text { Coptotermes } & \text { (termites; } \\
\text { Blattodea } & \text { [Isoptera]: } \\
\text { Termitoidea) } & \end{array}$ & $\begin{array}{l}\text { Logno } \\
\text { rmal }\end{array}$ & 70 & None \\
\hline $\begin{array}{l}\text { Planas \& } \\
\text { Ribera (2014) }\end{array}$ & $\begin{array}{l}\text { Loxosceles (spiders; } \\
\text { Araneae: Sicariidae) }\end{array}$ & $\begin{array}{l}\text { Expon } \\
\text { ential }\end{array}$ & 21.99 & $\begin{array}{l}10-20 \% \text { higher than } \\
\text { fossil age (Hipsley et } \\
\text { al., 2009) }\end{array}$ \\
\hline $\begin{array}{ll}\text { Price et al } \\
\underline{(2014)}\end{array}$ & Cephalotes (turtle ants) & $\begin{array}{l}\text { Logno } \\
\text { rmal }\end{array}$ & 65 & $\begin{array}{l}\text { Based on the age of a } \\
\text { previously dated node }\end{array}$ \\
\hline$\frac{\text { Ward et al. }}{(2008)}$ & $\begin{array}{l}\text { Azteca } \\
\text { (ants) }\end{array}$ & $\begin{array}{l}\text { Logno } \\
\text { rmal }\end{array}$ & 70 & None \\
\hline $\begin{array}{l}\text { Wood et al. } \\
\underline{(2013)}\end{array}$ & $\begin{array}{l}\text { Lycosidae sp. and } \\
\text { Gnaphosidae sp. (spiders) }\end{array}$ & $\begin{array}{l}\text { Logno } \\
\text { rmal }\end{array}$ & 42.6 & $\begin{array}{l}\text { Lower bound plus 20- } \\
30 \mathrm{Ma}\end{array}$ \\
\hline
\end{tabular}


Table 2. Summary of dating analyses with different clock and age prior settings.

(The following table is in embedded here as a figure, as the dimension of the table does not fit well. A separate Excel file for this table is attached with the submission.)

\begin{tabular}{|c|c|c|c|c|c|c|}
\hline \multirow[b]{2}{*}{$\#$} & \multirow[b]{2}{*}{$\begin{array}{l}\text { clock } \\
\text { model }\end{array}$} & \multirow[b]{2}{*}{ Age prior } & \multicolumn{4}{|c|}{ Median age estimates (95\% HPD) } \\
\hline & & & $\begin{array}{l}\text { Exophthalmus genus } \\
\text { complex }\end{array}$ & $\begin{array}{l}\text { "Entiminae } \\
\text { sp.GZ34-Entiminae } \\
\text { sp. 6" clade }\end{array}$ & $\begin{array}{c}\text { "Compsoricus } \\
\text { maricao-Tropirhinus } \\
\text { sp.GZ50" clade }\end{array}$ & $\begin{array}{l}\text { "Exophthalmus } \\
\text { roseipes-Diaprepes } \\
\text { marginicollis" clade }\end{array}$ \\
\hline 1 & linked & $\log n$ & $24.57(18.01-33.38)$ & $28.03(19.94-38.47)$ & $20.27(15.64-27.49)$ & $-24.11)$ \\
\hline 2 & linked & Exponential & $25.28(20.16-36.64)$ & $29.15(22.54-42.81)$ & $21.10(16.03-30.34)$ & $18.30(16.00-26.11)$ \\
\hline 3 & unlinked & Log normal & $22.93(17.94-31.98)$ & $24.45(18.70-34.22)$ & $18.85(15.58-26.05)$ & $17.79(13.90-24.56)$ \\
\hline 4 & unlinked & Exponential & $24.06(19.48-34.85)$ & $25.79(20.38-37.94)$ & $19.94(16.00-28.79)$ & $18.37(16.00-26.36)$ \\
\hline
\end{tabular}

Table 3. Dispersal rate multipliers between areas specified for the M1 constraint to model water currents.

\begin{tabular}{|c|c|c|c|c|c|c|c|}
\hline Area & $S$ & $\mathrm{~L}$ & $\mathrm{P}$ & $\mathrm{H}$ & $\mathrm{J}$ & $\mathrm{U}$ & $\bar{C}$ \\
\hline \multirow{4}{*}{$\underset{\mathbb{T}}{\mathbb{E}}$} & 1 & 1 & 1 & 1 & 1 & 1 & 1 \\
\hline & 0.5 & 1 & 1 & 1 & 1 & 1 & 1 \\
\hline & 0.5 & 0.5 & 1 & 1 & 1 & 1 & 1 \\
\hline & 0.5 & 0.5 & 0.5 & 1 & 1 & 1 & 1 \\
\hline \multirow{3}{*}{ 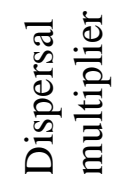 } & 0.5 & 0.5 & 0.5 & 0.5 & 1 & 1 & 1 \\
\hline & 0.5 & 0.5 & 0.5 & 0.5 & 0.5 & 1 & 1 \\
\hline & 0.5 & 0.5 & 0.5 & 0.5 & 0.5 & 0.5 & 1 \\
\hline
\end{tabular}

Table 4. Comparison of models with and without $\mathrm{J}$ and two model constraints. M0 - no dispersal multiplier is applied. M1 - dispersal in the same direction of the prevailing water currents in the Caribbean is assigned a larger dispersal multiplier than that oriented against the water currents.

\begin{tabular}{|c|c|c|c|c|c|c|c|}
\hline \multirow{2}{*}{ Model } & \multirow{2}{*}{$\begin{array}{l}\text { Con- } \\
\text { straint }\end{array}$} & \multirow[b]{2}{*}{$\operatorname{Ln} L$} & \multicolumn{3}{|c|}{ Parameter estimates } & \multirow{2}{*}{$\begin{array}{l}\begin{array}{l}\text { Likelihood- } \\
\text { ratio test }\end{array} \\
P\end{array}$} & \multirow{2}{*}{$\begin{array}{l}\text { AIC } \\
\text { analysis } \\
\text { weight } \\
\text { ratio }\end{array}$} \\
\hline & & & $d$ & $e$ & $j$ & & \\
\hline DEC & M0 & -165.3 & 0.0029 & 0.0074 & 0.000 & & \\
\hline $\mathrm{DEC}+\mathrm{J}$ & M0 & -116.7 & 0.0000 & 0.0000 & 0.038 & $6.2 \mathrm{E}-23$ & $4.79 E+20$ \\
\hline DIVALIKE & M0 & -162.1 & 0.0034 & 0.0024 & 0.000 & & \\
\hline DIVALIKE+J & M0 & -116.4 & 0.0000 & 0.0000 & 0.039 & $1.3 \mathrm{E}-21$ & $2.39 E+19$ \\
\hline BAYAREALIKE & M0 & -176.9 & 0.0017 & 0.0474 & 0.000 & & \\
\hline BAYAREALIKE+J & M0 & -119.5 & 0.0000 & 0.0000 & 0.040 & $8.7 \mathrm{E}-27$ & $3.11 \mathrm{E}+24$ \\
\hline DEC & M1 & -165.4 & 0.0044 & 0.0071 & 0.000 & & \\
\hline $\mathrm{DEC}+\mathrm{J}$ & M1 & -115.7 & 0.0000 & 0.0000 & 0.062 & $2 \mathrm{E}-23$ & $1.47 \mathrm{E}+21$ \\
\hline DIVALIKE & M1 & -163.1 & 0.0052 & 0.0010 & 0.000 & & \\
\hline DIVALIKE+J & M1 & -115.4 & 0.0000 & 0.0000 & 0.063 & $1.5 \mathrm{E}-22$ & $2.02 \mathrm{E}+20$ \\
\hline BAYAREALIKE & M1 & -176.4 & 0.0028 & 0.0476 & 0.000 & & \\
\hline BAYAREALIKE+J & M1 & -118.2 & 0.0000 & 0.0000 & 0.064 & 4E-27 & $6.72 \mathrm{E}+24$ \\
\hline
\end{tabular}




\section{Figure captions}

[We opt for black and white for the printed version for all figures]

Figure 1. Sampling localities for the Exophthalmus genus complex; (a) and dorsal habitus images of representative species (b). Top: Exophthalmus aff. annulonotatus sp.GZ73, Exophthalmus impositus, Exophthalmus jekelianus, Exophthalmus nr. humeridens sp.GZ49, Exophthalmus nr. viridis sp.GZ45, Exophthalmus quadrivittatus. Middle: Exophthalmus quindecimpunctatus, Exophthalmus roseipes, Exophthalmus scalaris, Exophthalmus similis, Exophthalmus triangulifer, Chauliopleurus adipatus. Bottom: Diaprepes boxi, Pachnaeus sp.GZ1, Tetrabothynus spectabilis, Tropirhinus sp.38, Tropirhinus sp.GZ46, Tropirhinus sp.GZ47.

Figure 2. Maximum clade credibility phylogeny of the Exophthalmus genus complex, derived from a Bayesian analysis employing a relaxed molecular clock. Numbers next to nodes are posterior probabilities and horizontal bars on the nodes indicate $95 \%$ intervals of ages.

Figure 3. Global ancestral range estimates for the Exophthalmus genus complex under the M1 constraint - i.e., dispersal rates between islands are defined according to the direction of oceanic currents - and using the model DIVALIKE+J. The estimation was performed with BioGeoBEARS, based on the chronogram generated with BEAST shown in Fig. 2. (a) Single most probable ancestral range is mapped at each node. The corner positions represent geographic range immediately after a cladogenetic event. (b) Pie charts indicate relative probabilities of all possible ancestral ranges (some of the possible ranges are not visible). Pie charts at corner positions are not shown. In both (a) and (b) the ancestral areas are omitted for nodes where no range change occurred (i.e., range copying). (c) Inter-island migration direction and frequency based on most probably ancestral range estimates in (a).

Figure 4. Comparisons of biogeographic estimations for the Exophthalmus genus complex under the M1 constraint using three biogeographic models - DIVALIKE, DEC, and BAYAREALIKE - while excluding the jump dispersal " $j "$ parameter. The estimations were performed with BioGeoBEARS, based on the chronogram generated with BEAST shown in Fig. 2. The single most probable ancestral range is mapped at each node. Corner positions represent geographic ranges immediately after a cladogenetic event. (a) DIVALIKE estimation. (b) DEC estimation. (c) BAYAREALIKE estimation.

Figure 5. Comparisons of biogeographic estimations for the Exophthalmus genus complex between models with and without jump dispersal, and with different model constraints (M0, M1). (a, b, c) Models that include founder-event jump dispersal, DIVALIKE $+\mathrm{J}, \mathrm{DEC}+\mathrm{J}$ and BAYAREA+J, all based on the M1 model constraint. (d, e) Estimations without any specific model constraint (M0). (f) Prevailing inter-island migration directions and frequency distributions according to different models or constraints. Asterisks (*) near boxes indicate different estimations from that in the "DIVALIKE+J, M1" result. 

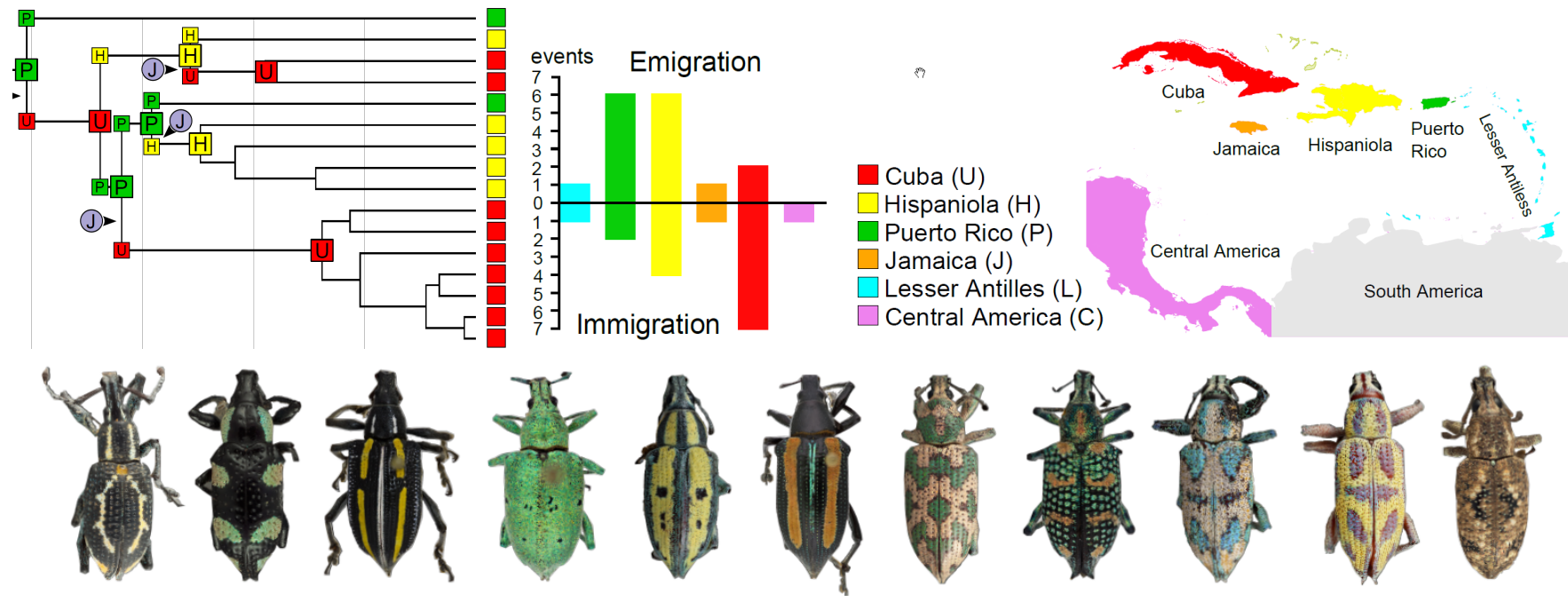

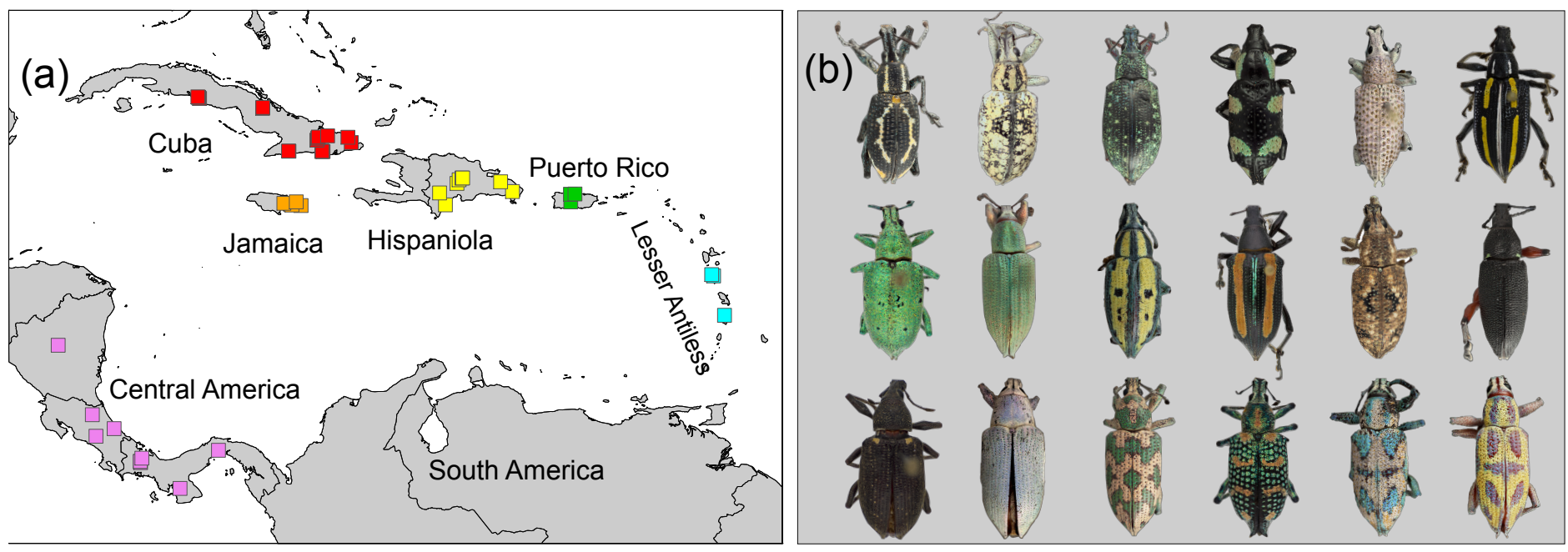

Figure 1. Sampling localities of the Exophthalmus genus complex (a) and dorsal habitus images of representative species (b) (Top: Exophthalmus aff. annulonotatus sp.GZ73, Exophthalmus impositus, Exophthalmus jekelianus, Exophthalmus nr. humeridens sp.GZ49, Exophthalmus nr. viridis sp.GZ45, Exophthalmus quadrivittatus. Middle: Exophthalmus quindecimpunctatus, Exophthalmus roseipes, Exophthalmus scalaris, Exophthalmus similis, Exophthalmus triangulifer, Chauliopleurus adipatus. Bottom: Diaprepes boxi, Pachnaeus sp.GZ1, Tetrabothynus spectabilis, Tropirhinus sp. 38, Tropirhinus sp.GZ46, Tropirhinus sp.GZ47.) 

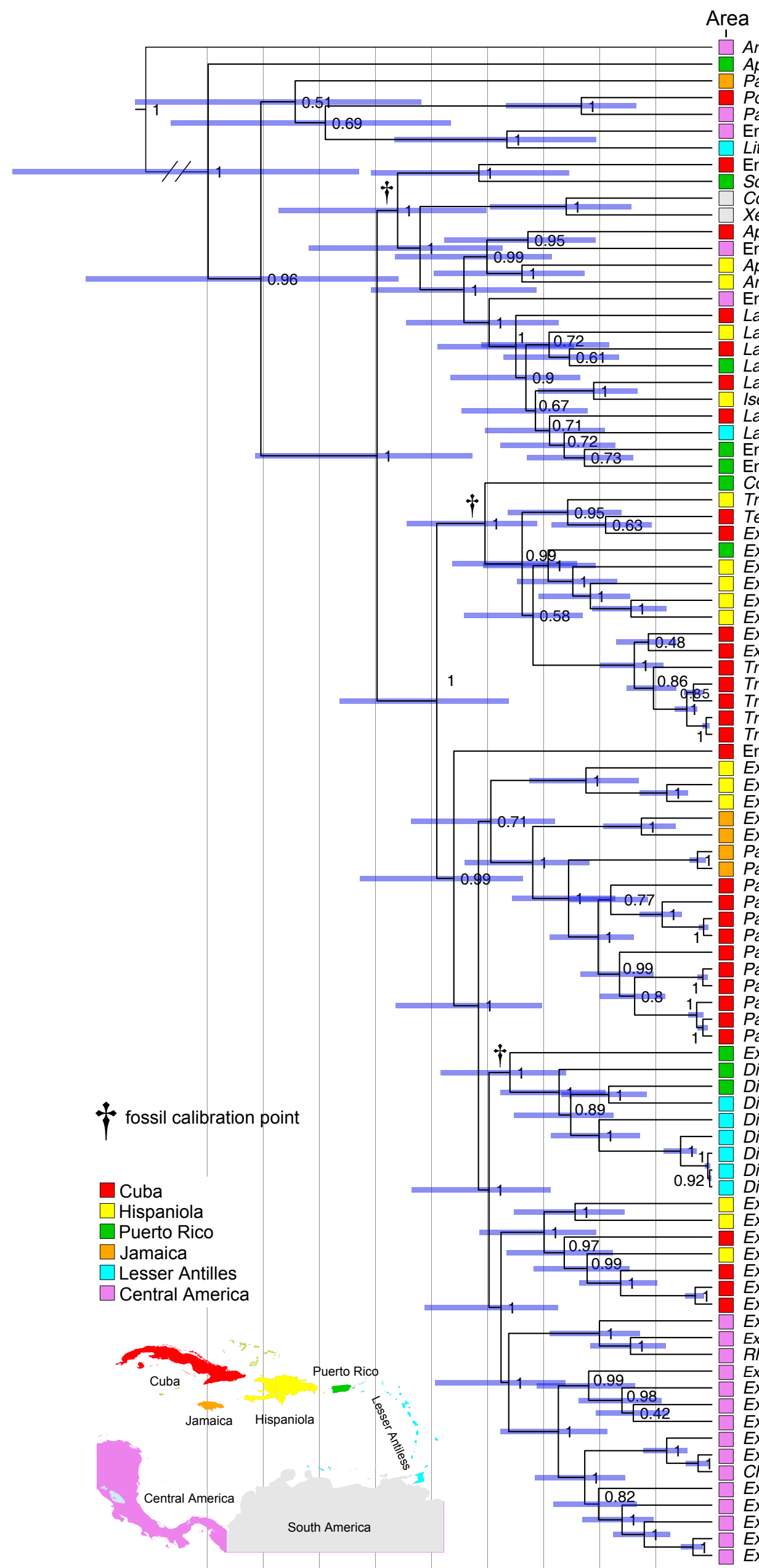

Anthonomus grandis

Apodrosus argentatus

Pandeleteius sp.1

Polydacrys sp.GZ37

Pandeleteius sp.GZ67

Entiminae sp.GZ81

Litostylus sp. 1

Entiminae sp.GZ34

Scelianoma elydimorpha

Compsus sp.GZ134

Xestogaster sp. 1

Apotomoderes sp.GZ59

Entiminae sp.GZ72

Apotomoderes menocrater

Artipus monae

Entiminae sp.GZ76

Lachnopus sp.GZ12

Lachnopus kofresi

Lachnopus sp.GZ22

Lachnopus seini

Lachnopus sp.GZ15

schionoplus niveoguttatus

Lachnopus sp.GZ9-1I

Lachnopus sp. 4

Entiminae sp. 5

Entiminae sp. 6

Compsoricus maricao

Tropirhinus sp. 38

Tetrabothynus spectabilis 623

Exophthalmus nr. viridus sp. GZ45

Exophthalmus quindecimpunctatus

Exophthalmus sp. 5

Exophthalmus sp. 4

Exophthalmus sp. 2

Exophthalmus sp. 3

Exophthalmus hybridus 670

Exophthalmus nr. humeridens sp.GZ49

Tropirhinus sp.GZ47

Tropirhinus sp.GZ2

Tropirhinus sp.GZ46

Tropirhinus elegans

Tropirhinus sp.GZ50

Entiminae sp.GZ51

Exophthalmus sp. 7

Exophthalmus sp. 8

Exophthalmus sp. 9

Exophthalmus similis

Exophthalmus vittatus

Pachnaeus marmoratus

Pachnaeus sp. 1

Pachnaeus sp.GZ38

Pachnaeus sp.GZ1

Pachnaeus sp.GZ52

Pachnaeus sp.GZ53

Pachnaeus sp.GZ13

Pachnaeus sp.GZ40

Pachnaeus sp.GZ25

Pachnaeus sp.GZ24

Pachnaeus sp.GZ6

Pachnaeus sp.GZ26

Exophthalmus roseipes

Diaprepes maugei

Diaprepes abbreviatus

Diaprepes sp. 1

Diaprepes famelicus

Diaprepes boxi

Diaprepes sp. 2

Diaprepes balloui

Diaprepes marginicollis

Exophthalmus cinerascens

Exophthalmus sp. 6

Exophthalmus scalaris

Exophthalmus quadrivittatus

Exophthalmus sulphuratus

Exophthalmus pictus

Exophthalmus pictus fulvovirgatus

Exophthalmus sp.GZ155

Exophthalmus aff. annulonotatus sp.GZ73

Rhinospathe albomarginata

Exophthalmus aff. vermiculatus sp.GZ165

Exophthalmus triangulifer

Exophthalmus impositus

Exophthalmus sp.GZ148

Exophthalmus sp.GZ166

Exophthalmus sp.GZ65

Chauliopleurus adipatus

Exophthalmus jekelianus

Exophthalmus sp.GZ151

Exophthalmus sp.GZ164

Exophthalmus sp.GZ82

Exophthalmus sp.GZ163

\begin{tabular}{ccc|ccccc|c|c|}
\hline \multicolumn{2}{c|}{ Eocene } & \multicolumn{2}{c|}{ Oligocene } & \multicolumn{3}{c|}{ Miocene } & Pli. & Plei \\
\hline 45 & 40 & 35 & 30 & 25 & 20 & 15 & 10 & 5 & 0 Ma
\end{tabular}

Figure 2. Maximum clade credibility phylogeny of the Exophthalmus genus complex derived from a Bayesian analysis employing a relaxed molecular clock. Numbers next to nodes are posterior probabilities and horizonal bars on nodes indicate $95 \%$ intervals of ages. 
(a) Single most probable ancestral range mapped and jump dispersals indicated

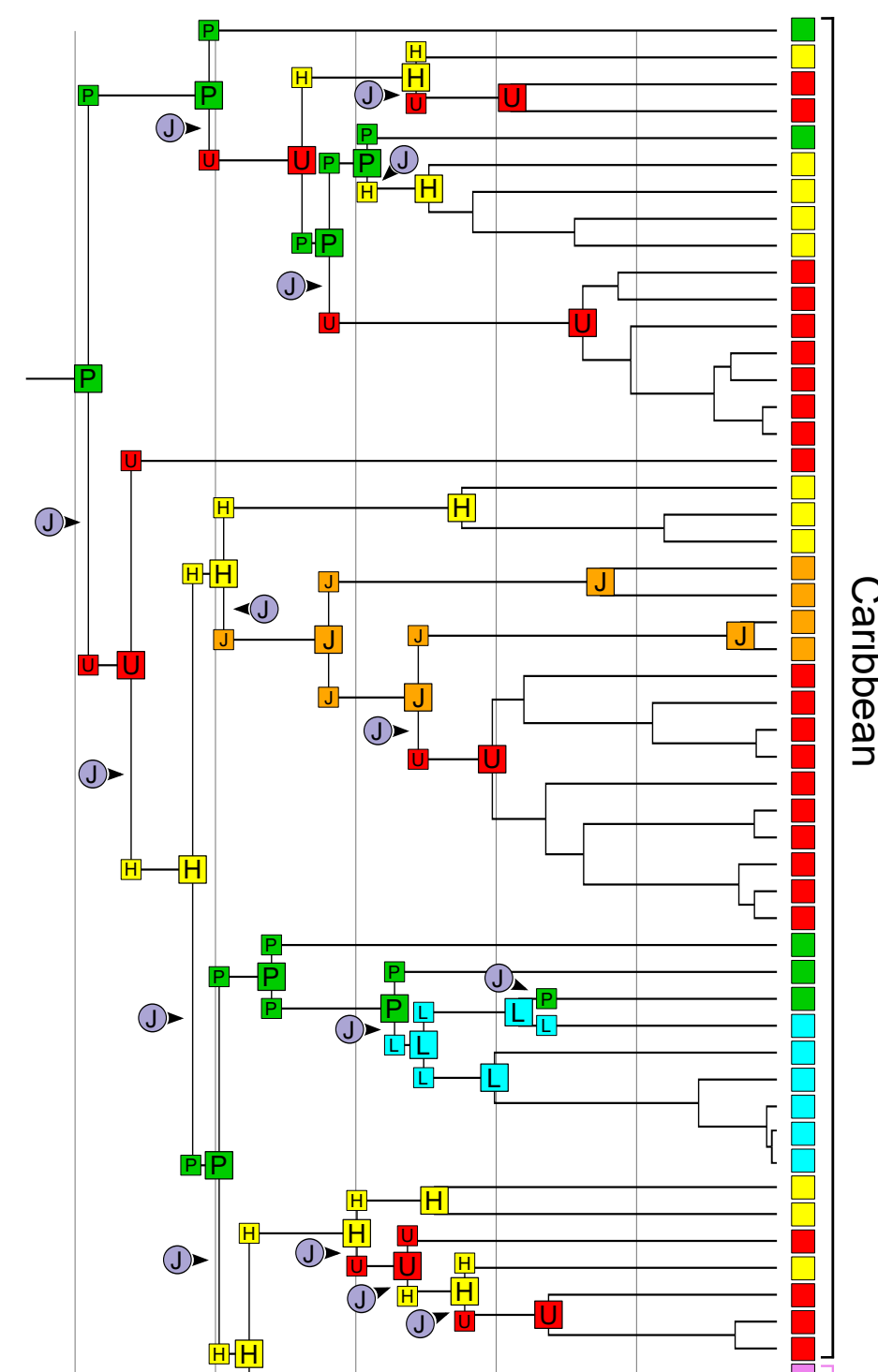

Colonization of Central America
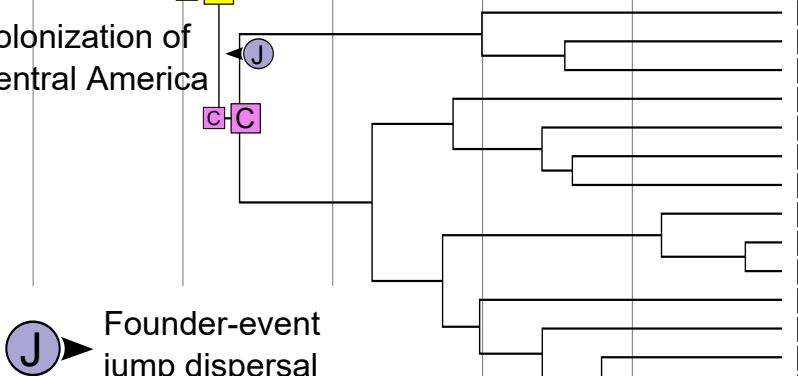

Founder-event jump dispersal

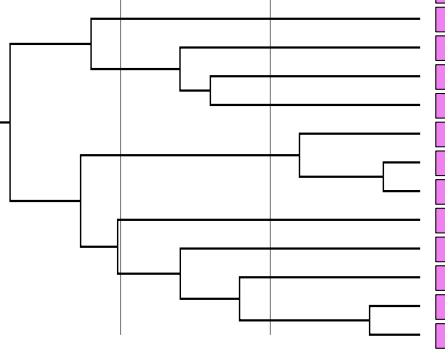

(b) Relative probabilties of all possible ancestral ranges indicated by pie charts

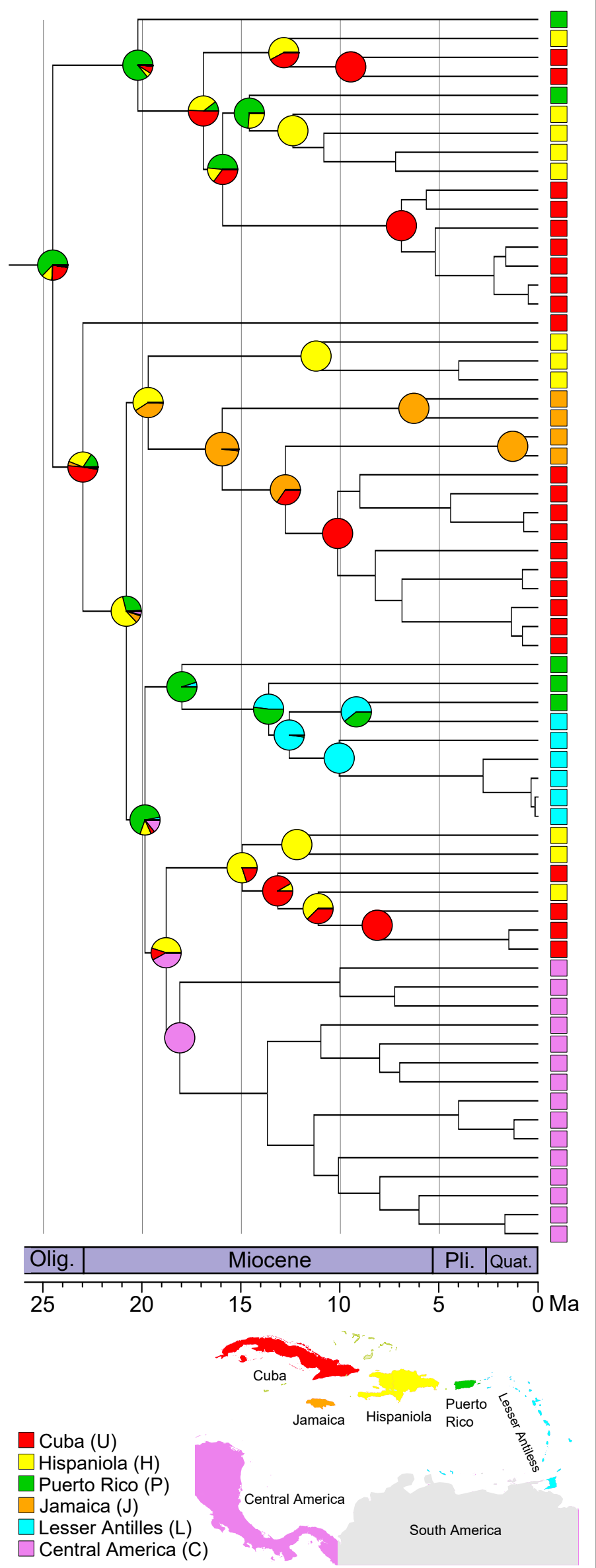

Fig. 3 Global ancestral range estimates of the Exophthalmus genus complexunder the M1 constraint (i.e., dispersal rates between islands are defined according to the direction of oceanic currents) using DIVALIKE+J. The estimation was performed with BioGeoBEARS, based on the chronogram generated with BEAST. (a) Single most probable ancestral range is mapped at each node. The corner positions represent geographic range immediately after a cladogenesis event. (b) Pie charts indicate relative probabilities of all possible ancestral ranges (some of the possible ranges are not visible). Pie charts at corner positions are not shown. In both (a) and (b) the ancestral areas are omitted for nodes where no range change occured (i.e., range copying). (c) Inter-island migration direction and frequency based on most probably ancestral range estimates in (a). 
(a)
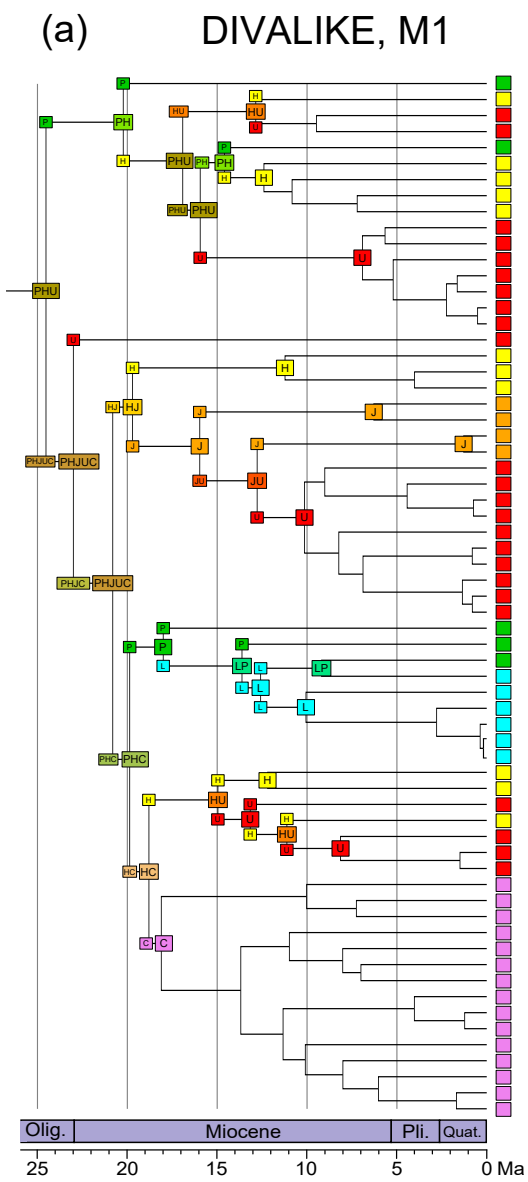

(b)

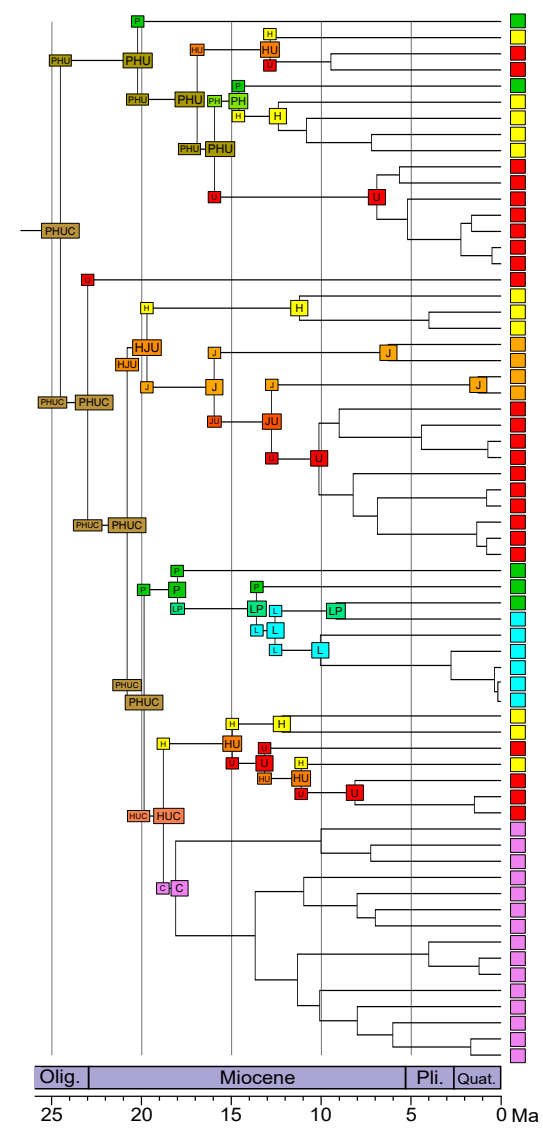

(b) BAYAREALIKE, M1

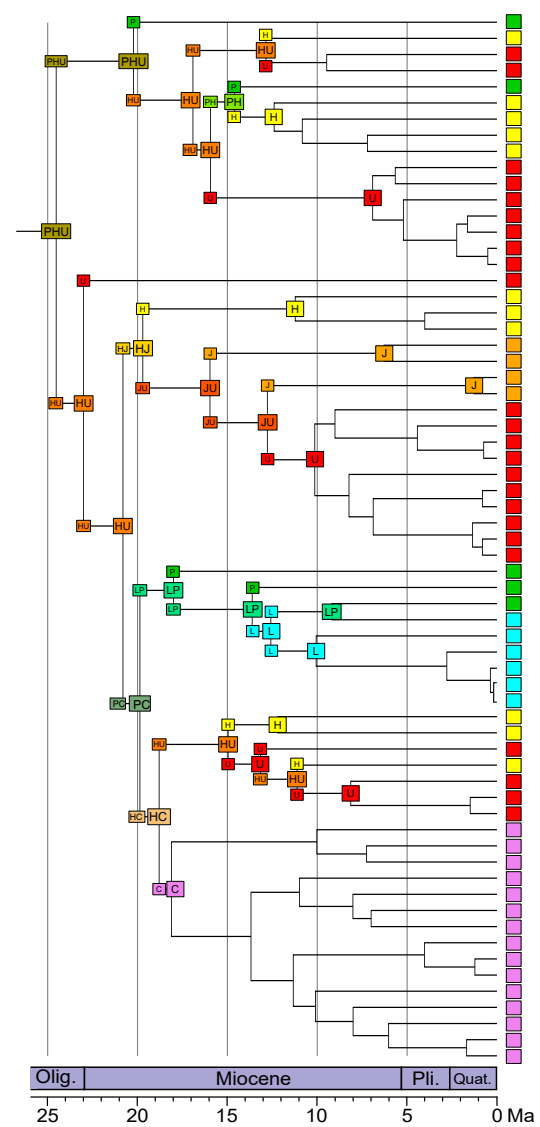

Fig. 4 Comparison of biogeographic esitmations of the Exophthalmus genus complex under the M1 constraint using three biogeographic models, DIVALIKE, DEC and BAYAREALIKE, not including jump dispersal "J". The estimations were performed with BioGeoBEARS, based on the chronogram generated with BEAST shown in Fig. 2. Single most probable ancestral range is mapped at each node. Corner positions represent geographic ranges immediately after a claogenesis event. (a) DIVALIKE estimation. (b) DEC estimation. (c) BAYAREALIKE estimation. 
(a) DIVALIKE+J, M1

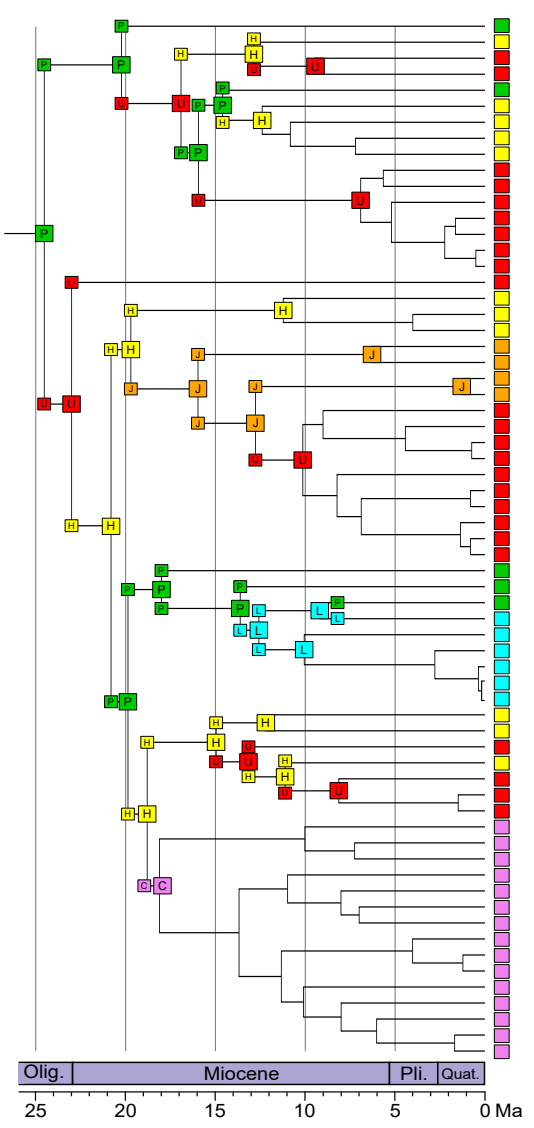

(d) DIVALIKE+J, MO

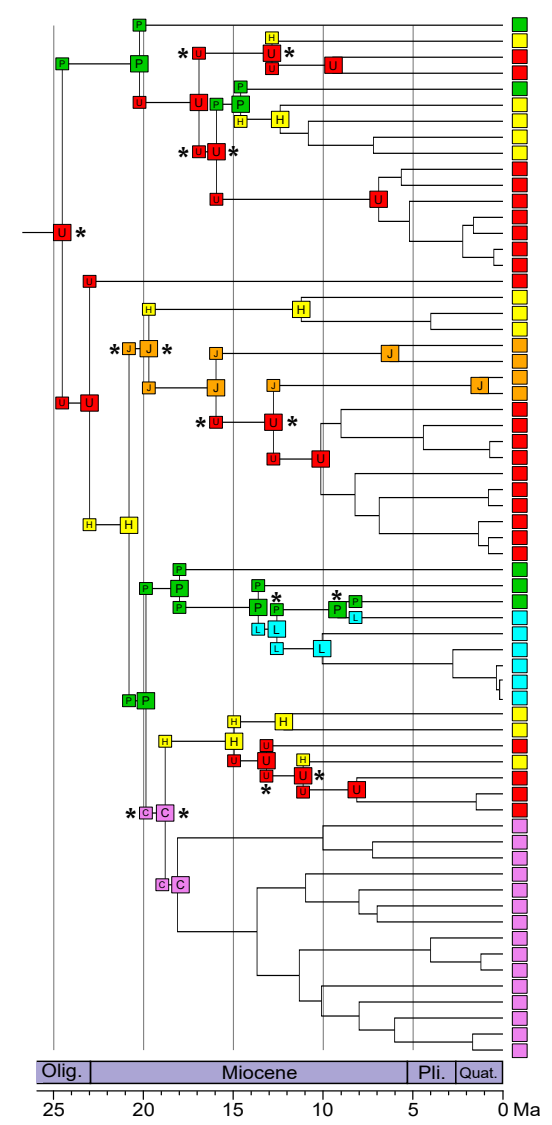

(b)

$\mathrm{DEC}+\mathrm{J}, \mathrm{M} 1$

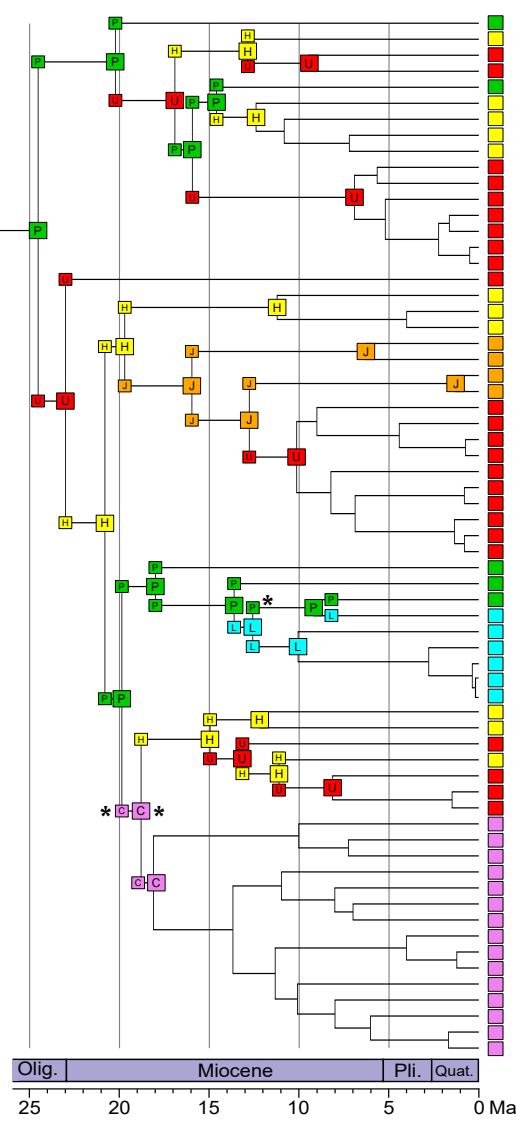

(e) DEC+J, MO

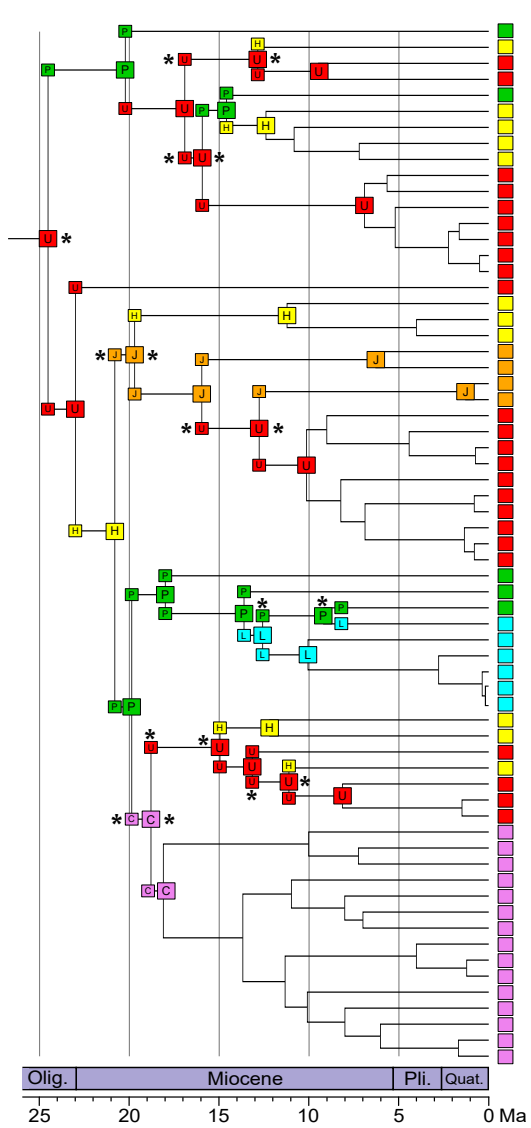

(c) BAYAREALIKE+J, M1

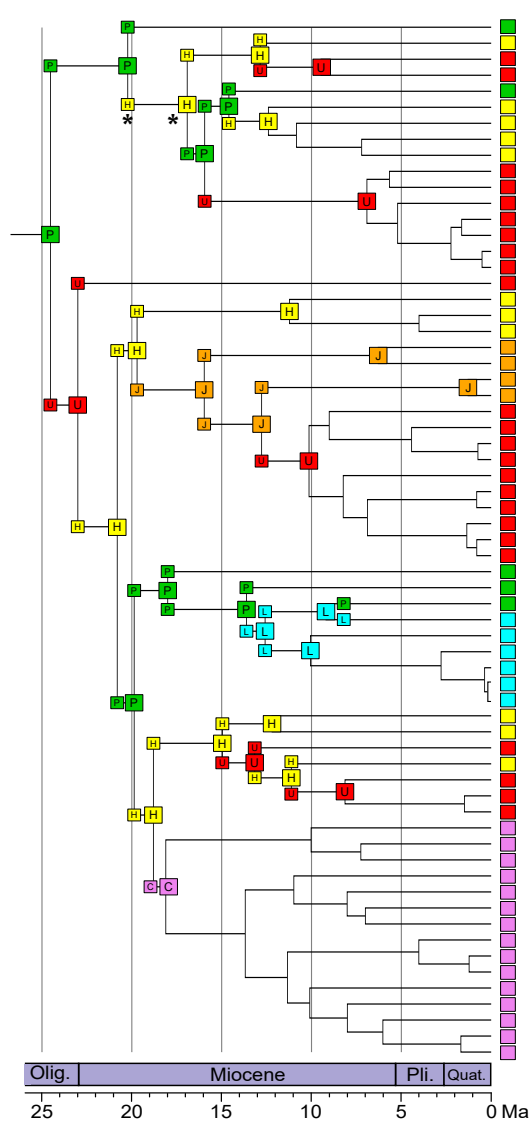

(f)

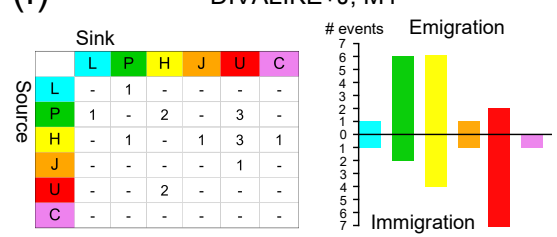

$\mathrm{DEC}+\mathrm{J}, \mathrm{M} 1$

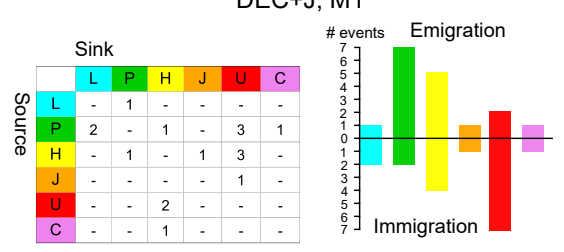

BAYAREALIKE+J, M1

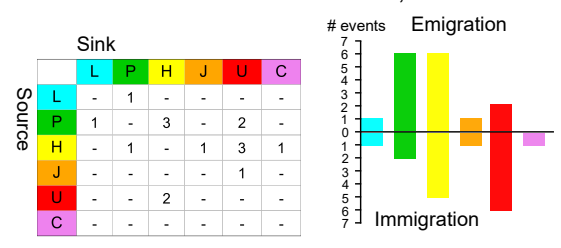

DIVALIKE+J, M0

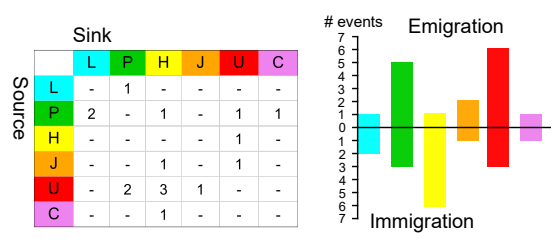

Figure 5. Comparisons of biogeographic estimations of the Exophthalmus genus complex between models with and without jump dispersal, and with different model constraints (M0, M1). (a, b, c) Models that include founder-event jump dispersal, DIVALIKE $+\mathrm{J}, \mathrm{DEC}+\mathrm{J}$ and BAYAREA $+\mathrm{J}$, all based on the M1 model constraint. (d, e) Estimations without any specific model constraint (M0). (f) Inter-island migration directions and frequency distributions according to different models or constraints. Stars $\left({ }^{*}\right)$ next to boxes indicate different estimations from that in the "DIVALIKE+J, M1" result. 


\begin{tabular}{lllcc}
\hline & & & Median age estin \\
\cline { 3 - 4 }$\#$ & clock & Age prior & $\begin{array}{c}\text { Exophthalmus genus } \\
\text { complex }\end{array}$ & $\begin{array}{c}\text { "Entiminae } \\
\text { sp.GZ34-Entiminae sp. } \\
\end{array}$ \\
& & & 6 " clade \\
\hline 1 & linked & Log normal & $24.57(18.01-33.38)$ & $28.03(19.94-38.47)$ \\
2 & linked & Exponential & $25.28(20.16-36.64)$ & $29.15(22.54-42.81)$ \\
3 & unlinked & Log normal & $22.93(17.94-31.98)$ & $24.45(18.70-34.22)$ \\
4 & unlinked & Exponential & $24.06(19.48-34.85)$ & $25.79(20.38-37.94)$ \\
\hline
\end{tabular}

